\title{
Mismatch negativity: translating the potential
}

\author{
Juanita Todd 1,2,3,4 *, Lauren Harms ${ }^{1,2,3,4}$, Ulrich Schall ${ }^{2,3,4,5}$ and Patricia T. Michie ${ }^{1,2,3,4}$ \\ ${ }^{1}$ School of Psychology, University of Newcastle, Callaghan, NSW, Australia \\ 2 Priority Research Centre for Brain and Mental Health, University of Newcastle, Callaghan, NSW, Australia \\ ${ }^{3}$ Schizophrenia Research Institute, Darlinghurst, NSW, Australia \\ ${ }^{4}$ Hunter Medical Research Institute, Newcastle, NSW, Australia \\ ${ }^{5}$ School of Medicine and Public Health, University of Newcastle, Callaghan, NSW, Australia
}

\section{Edited by:}

André Schmidt, University of Basel, Switzerland

\section{Reviewed by:}

Philip R. Corlett, Yale School of Medicine, USA

Karsten Heekeren, University Hospital for Psychiatry Zurich, Switzerland Andreea Oliviana Diaconescu,

University of Zurich, Switzerland; ETH Zurich, Switzerland

\section{*Correspondence:}

Juanita Todd, School of Psychology, University of Newcastle, University

Drive, Callaghan, NSW 2308, Australia

e-mail: juanita.todd@

newcastle.edu.au
The mismatch negativity (MMN) component of the auditory event-related potential has become a valuable tool in cognitive neuroscience. Its reduced size in persons with schizophrenia is of unknown origin but theories proposed include links to problems in experiencedependent plasticity reliant on $\mathrm{N}$-methyl-d-aspartate glutamate receptors. In this review we address the utility of this tool in revealing the nature and time course of problems in perceptual inference in this illness together with its potential for use in translational research testing animal models of schizophrenia-related phenotypes. Specifically, we review the reasons for interest in $\mathrm{MMN}$ in schizophrenia, issues pertaining to the measurement of MMN, its use as a vulnerability index for the development of schizophrenia, the pharmacological sensitivity of MMN and the progress in developing animal models of MMN. Within this process we highlight the challenges posed by knowledge gaps pertaining to the tool and the pharmacology of the underlying system.

Keywords: mismatch negativity, auditory event-related potential, schizophrenia, NMDA, synaptic plasticity, NMDAR
With more than 150 papers discussing or reporting smaller mismatch negativity (MMN) amplitude in schizophrenia, changes in this component of the auditory event-related potential (ERP) are now recognized as one of the most replicable electrophysiological abnormalities in this group. This review begins with an explanation of why this finding holds so much potential as a tool in the study of biological changes associated with the schizophrenia illness. However, the sections that follow expose the many challenges to the endeavor to translate this research - both in terms of understanding the meaning, relevance, and cause of smaller MMN amplitude and in terms of building animal models that can provide insight into etiology.

\section{THE POTENTIAL - WHY IS THERE SO MUCH INTEREST IN MMN IN SCHIZOPHRENIA?}

Auditory MMN is evident in scalp-recorded evoked potentials when an unexpected event or sound transition occurs in a regular repeating pattern (1). MMN is not a response to novelty per se but rather to how unlikely a particular sound transition is given a preceding sequence (2). It is therefore a very context-dependent evoked potential that only occurs when a pre-existing predictionmodel exists specifying the most likely sound transitions in the present environment.

The nature of sound sequences used to elicit and study MMN range from very simple to highly complex. The vast majority of studies in schizophrenia employ the former in which a regular repeating identical sound occurs with high probability (the standard) and a physically deviant sound (the deviant) interrupts these repetitious trains on rare occasions (estimates suggest max $p \leq 0.30$ ) (3). Sequences of this kind, known as oddball sequences, promote the formation of a prediction-model specifying that acoustic input is best explained by standard-to-standard transitions and the rare occurrence of a standard-to-deviant transition is generally used to index MMN (although note that deviant-tostandard transitions also elicit a smaller MMN-like response). Regularities are implicitly learned as MMN does not require attention to sounds: sound sequences are usually presented via headphones to participants who are asked to ignore sounds and direct attention to an alternate task (3).

The classical derivation of MMN involves a deviant-minusstandard difference waveform with MMN quantified as the most negative peak evident between $\sim 100$ and $250 \mathrm{~ms}$ following the point of deviance (4). The quintessential finding in studies of this kind is that the averaged response to standard stimuli is similar in schizophrenia and matched control groups but the response to the deviant is significantly smaller resulting in smaller MMN in the difference waveform (5).

The major cortical sources contributing to scalp-recorded MMN are located bilaterally in primary and secondary auditory cortices with the precise locations dependent upon the sound characteristics (6). Intra-cortical recordings in primates suggest that the additional negativity in scalp-recorded response to deviations has its origin in lamina II/III of the auditory cortex (7). The neural mechanisms contributing to the difference in response to predicted versus deviating sound are the topic of considerable debate. There is general acceptance that processes such as neuronal adaptation make an important contribution; that is, the regular stimulation of the same afferent pathways will result in adaptation which reduces the response to sounds matching these properties, while in contrast deviating tones that are physically different will stimulate new afferent pathways (8-10). However, both sophisticated sequence designs and computational modeling 
support the existence of additional processes subserving prediction. Although some of these will be reviewed in more detail below (see The Measurement of MMN - Is there an Optimal Paradigm with Which to Study MMN in Schizophrenia?), extensive discussions can be found elsewhere (2, 3, 11-13). In summary, there is accumulating evidence that the altered responsiveness to sounds (reduced to expected and sensitized to deviant) cannot be explained by neuronal adaptation alone. Computational models suggest that predictions are expressed in the input from higher to lower levels within a hierarchical network $(11,12,14)$. Changed response to sound therefore becomes a function of both neuronal adaptation and top-down inputs to auditory cortex (e.g., from secondary to primary cortex and from prefrontal to secondary cortex) that modify responsiveness to sound reflecting the predicted continuation of a learned pattern.

A network-level appreciation of MMN generation is valuable because it emphasizes that understanding the smaller MMN amplitude in schizophrenia could require consideration of both cause and consequence, acknowledging the functional role of the signal. According to free-energy conceptualizations of brain function, prediction-modeling (the use of regularity to extrapolate patterns) provides a regulatory service allowing the brain to conserve energy (15). Reduced response to the predicted causes of sensory stimulation, such as diminished response to standard input, reserves resources for events that contradict expectations and that may signal important changes in the environment prompting new learning. MMN signals a prediction-error indicating that the model presently influencing cortical response has failed to account for the current sensory event. The error communicates a need to adjust the current model to facilitate more accurate predictions, and simultaneously alerts the system to the possible importance of the eliciting event $(15,16)$. The error is communicated upward (via feed-forward connections) within a hierarchical network which enables future predictions to be weighted by error frequency (17). When a model is highly reinforced (low error frequency) predictions specified in top-down connections are weighted strongly and errors elicit large MMN. Conversely, when error frequency is higher the weighting on top-down predictions is reduced and MMN elicited by errors is smaller in amplitude. This concept has elsewhere been described as predictive confidence in a model which is of course inversely related to the probability of deviations (2). MMN amplitude therefore reflects quantification of confidence that the eliciting event violates a contextual regularity. Large MMN can trigger an orienting response with consequences for performance of concurrent tasks (18-23). These observations demonstrate the way in which a deviation from predictions can draw upon resources engaged in other activities.

In schizophrenia, MMN as a process appears to be largely intact in that it obeys similar principles to those evident in healthy comparison groups $-\mathrm{MMN}$ is larger for deviations that are rarer and/or more physically different from the current prediction-model (24). However, MMN amplitude reaches asymptote at a lower amplitude resulting in the most pronounced group differences generally being observed where MMN is very large in controls (25-27). Understanding the functional relevance of $\mathrm{MMN}$ amplitude is pivotal to understanding the potential impact of smaller MMN in schizophrenia. It has been proposed that MMN amplitude in part communicates the change in cortical responsiveness required to accommodate the new event into prediction-models (16). To the extent that this is true, the lower plateau in MMN amplitude in schizophrenia means that the adjustment to predictions prompted by larger or rare deviations may be equivalent to that for smaller or more frequent deviations. So if the size of the error-signal itself influences the adjustment in predictions, then equivalence of error signals across a range of deviant probabilities or physical differences (25-27) would perpetuate insensitivity to these different contexts.

This circular challenge becomes particularly relevant when considering how smaller $\mathrm{MMN}$ is related to biological changes associated with the illness, such as gray matter changes and involvement of the $N$-methyl-D-aspartate (NMDA) glutamate receptor (NMDAGluR) system. A key biological change observed in schizophrenia is loss of cortical gray matter volume (28-35). Within the auditory system this volume loss is due to a combination of reduced pyramidal somal cell size, reduced dendritic spine density, and (a correlated) reduction in axon terminal density in lamina III (36-39). Molecular-level studies in schizophrenia therefore place a core pathological process in the very same cortical layer implicated in the generation of MMN. The projected functional consequence of reduced volume in this cell layer is a net "diminished excitatory synaptic connectivity" consistent with an impact on the spread of activation [(36), p. 384]. The generation of MMN includes spreading activation across lamina III within A1 (Heschyl's gyrus or primary auditory cortex) but also importantly from A1 to STG [superior temporal gyrus or auditory association cortex $(11,17)$ ]. So in terms of MMN generation, this pathology in auditory cortical regions is expected to lead to smaller MMN generated in response to error and/or a lower limit to MMN size [consistent with experimental observations reviewed $(36,38)]$. This predicted consequence is also consistent with observations that in schizophrenia (but not in matched controls) limited MMN size correlates with reduced gray matter volume in auditory regions $(35,40)$ and in the only published longitudinal study, progressive loss of gray matter in auditory cortices correlated with progressive reduction in MMN (40).

The etiology of this auditory cortical pathology in schizophrenia is unclear but two hypotheses put forward include a developmental origin and/or failure in sustained support of structural integrity (36). The first supposes that there is an over-elimination of excitatory synapses in lamina III during development. Since this process is very protracted [continuing into the third decade in auditory cortices (41)], it maps well onto data showing progressive reductions in STG gray matter volume in schizophrenia over this period (42). However, experience-dependent plasticity modifies dendritic spine structure throughout life (through long term potentiation and depression) and this activity has a stabilizing effect on these structural elements. The same pathology could therefore also arise (uniquely or in conjunction with developmental over-pruning) through failure in the factors that should support structural integrity.

The second and not unrelated biological factor with relevance for smaller MMN in schizophrenia is the impairment in NMDAGluR system function proposed in glutamatergic models of schizophrenia which have become increasingly accepted 
as etiopathological models of schizophrenia. These models arose from observations that the drug phencyclidine (PCP) has (i) psychotomimetic effects and (ii) non-competitively blocks NMDAGluRs [for detailed reviews see Ref. (43-45)]. NMDAGluRs have a key role to play in experience-dependent synaptic plasticity, and in particular long term potentiation and depression. Importantly (as reviewed later in Section "How do Pharmacological Manipulations Alter the MMN Process?”), MMN is reduced in healthy individuals administered an NMDAGluR antagonist, such as ketamine. So the question that emerges is this: is smaller $\mathrm{MMN}$ in schizophrenia a consequence of gray matter reduction and/or NMDAGluR hypofunction in auditory cortex, or could the process of prediction-modeling in audition provide clues as to why structural integrity in this region is inadequately supported? In summary, the reasons to suppose that MMN can be used as tool to provide insights into schizophrenia-related brain changes are many and derive from both empirical and theoretical origins. In the following sections we review MMN research from several perspectives to identify some important challenges to realizing its potential in the study of biological processes linked to schizophrenia.

\section{THE MEASUREMENT OF MMN - IS THERE AN OPTIMAL PARADIGM WITH WHICH TO STUDY MMN IN SCHIZOPHRENIA?}

Smaller MMN in schizophrenia has been observed over a number of different experimental paradigms so the underlying reasons for MMN-reduction are likely to reflect the common demands inherent in processing the various sound sequence types. Different paradigms each have advantages and disadvantages (reviewed below) and it is the authors' opinion that there is no ideal paradigm. In fact, to nominate an ideal could be detrimental to the field - the advantage in doing so (increased comparability between studies) is outweighed by the disadvantage which is neglect of the opportunities to use this tool to address specific questions about the integrity of the underlying system.

\section{CONSIDERATIONS IN MEASURING A DIFFERENCE WAVEFORM}

There are at least three contributing factors to MMN obtained in the classical deviant-minus-standard waveform: (i) differences in physical attributes of the deviant and standard sounds (this is particularly likely when the deviant contains physical features that vary in acoustic energy such duration or intensity), (ii) differences in refractoriness (or more properly called adaptation) of the neural generators of responses to the more frequently presented standard versus rare deviant stimulus and (iii) a genuine deviancedetection process or the true $M M N$ resulting from the deviant violating predictions derived from contextual regularities. This means that a group difference in classically derived MMN could arise from any one or a combination of these factors. A number of experimental control protocols have been developed to refine a measure of true $M M N$ - the primary motivation for these studies being to determine whether a true MMN exists or whether what is measured as MMN could be accounted for entirely by adaptation effects on other components of the ERP. In a series of papers, Schröger and his colleagues devised a random control stimulus sequence, the many-standards sequence. For example in the case of a frequency deviant, a many-standards control would involve random presentations of tones of different frequencies (including tones with the frequencies of the deviant and standard tone) each having the same probability as the deviant in the oddball sequence [Frequency/pitch: (46-48); Duration: (49); Location: (50)]. A comparison of responses to the deviant from an oddball sequence and to the same sound in a many-standards sequence controls for physical differences and adaptation contributions to the classically derived MMN. In this way the resultant difference waveform can be attributed to a novel event violating a stored neural representation of regularity in recent stimulation. This is because the random presentation order of the many-standards sequence prevents the development of a representation of regularity in recent stimulation but preserves the rate of occurrence and therefore some level of equivalence in terms of adaptation effects.

To our knowledge there are no studies that have implemented conservative control procedures to extract true MMN in schizophrenia. As noted above, the vast majority of the published literature in schizophrenia has employed MMN derived using the classical oddball derivation. The common finding of similar responses to standards in schizophrenia and matched control groups is reassuring in that it suggests that adaptation effects on the standard response at least are not detectably impaired in patients and implies that the major group differences are in how the brain responds to deviations. However whether there are group differences in the extent of cross adaptation to other frequencies (or durations/intensities, etc., in the case of simple deviance paradigms) is unknown and this could impact on the response to a physically different deviant tone. It is also reassuring to note that in healthy individuals, even when stringent controls such as the many-standards control are implemented, the classical derivation gives a reasonable approximation of the true MMN (49). But once again - whether this is equally true in patients is unknown. Below we review some of the literature employing non-classical MMN derivations indicating that there may indeed be some group differences in response to repetitive sound as well as the response to deviations.

\section{EXAMPLES OF PARADIGMS USED IN SCHIZOPHRENIA}

A few patient studies have employed methods that can differentiate components of the MMN process and these have yielded mixed findings. Some have controlled for the physical differences between standard and deviants sounds, either by presenting two oddball sequences with the roles of deviant and standard sounds reversed [a flip-flop design: $(51,52)$ ] or by presenting a sequence consisting of repeated presentations of deviant sounds only (53), referred to as a deviant-as-standard sequence. In both instances, it is possible to derive difference waveforms from comparing responses to the same sound as a repetitive standard and a deviant event. While these studies report no group difference in response to the repetitive oddball standard presentations, Todd et al. (54) recently found evidence of clear group differences in the morphology of ERPs to the repetitious presentation of deviants and these differences had a significant impact on computation of the MMN. The group difference appeared in a negative component of the ERP to repetitive sounds occurring $\sim 200-300 \mathrm{~ms}$ post-stimulus. While its origin and functional role are unknown, it suggests that such 
differences in cortical response to a repetitive sound more generally warrant further investigation. However, neither the flip-flop control nor the deviant-as-standard sequence removes the contribution of adaptation effects to the difference waveform. Nor does it ensure that the computed MMN represents true deviance detection of a violation of contextual regularity. That is, these procedures do not allow the extraction of the true MMN.

The roving paradigm is another method that can partially address group differences in various contributions to MMN. In a typical roving paradigm a string of sounds of the same pitch are eventually interrupted by a sound with a higher or lower pitch which then continues to repeat. Predictive processing is highly dynamic so within two to three repetitions, the new sound becomes a standard and deviations from its properties will now elicit MMN (55-57). In the roving paradigm, it is possible to study the way the response to a new standard changes after incremental repetitions (e.g., 6 vs. 12 vs. 24, etc.). An increasing positivity as a function of repetition length, termed "repetition positivity," is apparent in the ERP to standards approximately 50-200 ms poststimulus. The increase in MMN amplitude with the length of repetition is referred to as a memory trace effect and is a function of both this apparent increased positivity (which is in fact a decrease in negativity) to the standard and increased negativity to a subsequent deviant [although see Ref. (58)]. In schizophrenia, the increment in both components is smaller than that in controls (59), but more notably in this study, the positivity in response to standard repetitions failed to increment at all. So in this paradigm smaller MMN in schizophrenia appears to indicate less change in responsiveness to sound generally.

In a recent magnetoencephalographic (MEG) study in schizophrenia (60), the $\mathrm{MMN}_{\mathrm{m}}$ data in a similar roving paradigm was explored using a technique called dynamic causal modeling (DCM). DCM differs from conventional source modeling and brain connectivity methods by utilizing a biologically informed causal model placing constraints on model inversion such that the parameters of reconstruction describe specific processes like change in synaptic coupling strength between source locations and postsynaptic gain. Rather than estimating dipole activity at a particular point in time; it models dipole activity over a period of time to identify parameters that change (11). When applied to the roving paradigm, DCM has provided evidence supporting the conceptualization of $\mathrm{MMN}$ as an active contextual perceptual inference process. The "best fit" to experimental data is achieved by a model that incorporates both local intrinsic adaptation effects as well as plastic changes in extrinsic inputs to auditory cortex (i.e., from STG to A1 and also from areas of the prefrontal cortex to STG). When applied to schizophrenia data, DCM has provided evidence for problems in two of three components: the largest effect size for group differences was for reduced change in intrinsic connections within primary auditory cortex A1. Such changes are considered evidence of impaired feature specific adaptation. There was also a reversed polarity in changes to connectivity between prefrontal and auditory areas which was interpreted as a failure in the normal influence of these top-down inputs in modifying auditory cortical response. The authors also comment on reduced modulation of the forward connection from the A1 to the STG (but this was not significant according to Table 2, p. 26). Although this is the first study of its kind in schizophrenia, the results conform to the view that impaired signaling of error (smaller MMN) could be indicative of impairment in encoding the contextual memory against which deviance is registered (potentially including impaired adaptation), but also consequently impaired ongoing modification of cortical responsiveness by feedback projections. It is therefore possible that the roving standard paradigm is more sensitive to any problems in forming a contextual memory based on tone repetitions. However, when interpreting results it is important to consider the assumptions of the roving paradigm carefully before drawing this conclusion. The MMN elicited to a change in frequency in a roving paradigm signals that the current prediction-model failed to account for the present stimulus properties and the model may require updating. With repetition of the new frequency, an updated prediction-model is built. The degree to which the model requires updating will be a function of the difference between the representation of the new and former standard frequencies. Given that the changes in frequency can be quite subtle and that frequency discrimination is impaired in schizophrenia $(53,61,62)$, it is possible that less evidence of updating after a new standard (repetition positivity) could in part reflect less distinct representations of the new and former frequency. So the roving paradigm places considerable weight on stimulus-specific adaptation to a new frequency, which therefore may augment the importance of intrinsic adaptation in A1. Whether DCM of a classic oddball paradigm would replicate major group differences in intrinsic Al connections remains to be determined.

At present the literature certainly suggests that altered (smaller) response to sequence deviations is a major contributor to smaller MMN in schizophrenia. It is clear that the reduction in classical $\mathrm{MMN}$ is not only robust across many different cohorts, laboratories, ethnic groups, etc. (5), but also exhibits substantial stability over time (63). However there is reason to suppose that there may also be differences in responding to repetitive sound more generally that could be contributing to problems in prediction-modeling and/or MMN computation. Novel paradigms and novel data processing approaches are likely to provide valuable data with which to address these contributions. Despite these differences it should be noted that many elements of the predictive process underlying $\mathrm{MMN}$ remain intact in schizophrenia. In addition to those covered above we recently demonstrated that persons with schizophrenia, despite producing smaller MMN amplitude to deviants, are equally able to reduce MMN size to a deviant if the occurrence of that deviant could be inferred from the identity of the prior tone. The equivalent use of this predictive information in both schizophrenia and control group reinforces the position that abnormalities in the MMN process in schizophrenia primarily involve limited gain in the differential response to a very rare versus common event. So while the choice of paradigm used to study MMN in schizophrenia will depend not only on the questions driving your research but also the time you have available, the one principal recommendation that we do put forward is to ensure that you adopt a very rare deviant event $(<15 \%)$ to maximize your power to expose group differences. 


\section{DOES MMN-REDUCTION INDICATE VULNERABILITY TO SCHIZOPHRENIA?}

In this section we review studies addressing whether small MMN may be a vulnerability index for schizophrenia. It should be noted that research into schizophrenia has always been limited by its diagnostic heterogeneity and phenomenological overlap with related developmental, affective, or personality disorders which all can share some of the clinical features of schizophrenia, such as psychosis, cognitive impairment, or therapeutic response to certain classes of pharmacological agents (64). Not surprisingly, attempts to find a diagnostic marker for schizophrenia - that not only represents an endophenotype of the disorder but can also serve as a tool helping to unveil its pathology - continues to be limited by the lack of a pathogenomic definition of the condition. Diagnostic limitations notwithstanding, a number of groups have indeed investigated MMN's status as an endophenotype for schizophrenia as defined by current diagnostics tools and this research is pertinent to evaluating the translational potential of $\mathrm{MMN}$ in schizophrenia. The definition upon which the evaluation is based is that proposed by Gottesman and Gould (65) where an endophenotype is defined as an intermediate phenotype along the pathway between genotype and the observable established aspects of the illness. Specific criteria to be met include: (i) it is associated with illness in the population; (ii) it is heritable; (iii) it is primarily stateindependent (manifests in an individual whether or not illness is active); (iv) within families, small MMN and the illness cosegregate; and (v) smaller MMN is evident in non-affected family members at a higher rate than in the general population (65).

\section{CRITERION (I) AND (II)}

Mismatch negativity amplitude reduction in schizophrenia is a very robust finding with an effect size of 0.99 observed by Umbricht and Krljes (5) in their meta-analysis of 32 studies published prior to 2004. Reduced MMN is less prevalent in related conditions, such as bipolar affective disorder independent of the presence of psychotic symptoms $(52,66-68)$ and in major depression (66) but see (69-71). That is, there is considerable evidence that criterion (i) is met in terms of its association with the illness, although its specificity to schizophrenia is less clear than initially thought. MMN appears to be heritable based on twin studies with heritability estimates ranging from 0.48 to 0.68 when using a duration increment deviant $(67,72)$ but not for a frequency deviant (73). However, even duration MMN shows only weak phenotypic association (0.39) with schizophrenia (67). Nonetheless, there is preliminary evidence supporting criterion (ii) for endophenotypic status of MMN.

\section{CRITERION (III)}

Across the large number of studies on MMN in schizophrenia there are no consistent relationships between $\mathrm{MMN}$ size and the severity of symptoms of psychosis. Although impaired predictionerror signaling is implicated in the genesis of delusions (74) and although there is preliminary but consistent evidence from one group of a relationship with auditory hallucinations (75-77), the literature fails to demonstrate consistent relationships across studies. The meta-analysis by Umbricht and Krljes (5) emphasized that the majority of studies did not find correlations (either with positive or negative symptoms) and observed no change in MMN when symptoms improved. Further (63), found duration MMN in very large sample of patients $(N=163)$ exhibited substantial stability across a 1 year retest interval, and to be independent of fluctuations in clinical symptoms, positive or negative. So at face-value, these results from cross-sectional designs seem to support state-independence of presence of smaller MMN [criterion (iii) ]. However, the evidence about state-independence of degree to which MMN is reduced in patients in an acute phase vs. a postacute phase is mixed $(78,79)$ although differences due to medication changes cannot be eliminated (see later Section "How do Pharmacological Manipulations Alter the MMN Process?" for further discussion of state vs. trait effects on $\mathrm{MMN}$ as a vulnerability marker).

The failure to demonstrate state-dependence is paralleled by more consistent relationships between MMN amplitude and relatively stable features of the illness such as level of functioning (80) and cognitive impairments (81) despite substantial changes in negative and positive symptom severity. Various measures of current functioning have been shown to be associated with MMN amplitude in patients: global assessment of function [GAF: (82-84)], social and occupational functioning assessment scale [SOFAS; (35) but not in first episode patients (85)], the independent living scales [ILS: (86)], and work functioning and independent living ratings from the role functioning scale (87). It has been suggested that the relationship between reduced MMN and impaired functioning might be mediated by anatomical changes such as gray matter loss in relevant brain regions (35). Impaired cognition (whether independent of gray matter declines or consequential) could also mediate the relationship between MMN and functional status since there is a wealth of evidence now that the strongest predictor of functional outcomes in patients is cognition [also often called neurocognition: (88)]. However, the number of published MMN studies in schizophrenia that examine not only cognition in the same sample but correlations between MMN and cognitive performance as well, is quite limited. This is despite reasonable expectations that the reliance of MMN generation on the the NMDAGluR system (see How do Pharmacological Manipulations Alter the MMN Process? and Translation to Animal Models below for further discussion) should lead to relationships with those aspects of cognition that are also reliant on the unique characteristics of the NMDAGluR, such as context-dependent effects, integration of information over time and new learning (44). However, there are some data that suggest such relationships do exist at least in patients (but not necessarily in healthy controls).

NMDAGluRs have a number of unique features. Firstly, activation of NMDAGluRs currents is conditional in that channels only gate following presynaptic release of glutamate and concurrent postsynaptic membrane depolarization which relieves $\mathrm{Mg}^{2+}$ blockade. This conditional characteristic of the NMDAGluR is likely to be particularly important where responses are determined by context, as is the case for MMN, but also in situations where flexibility of response is required dependent on context. One specific example of contextual processing is the $\mathrm{AX}$ version of the continuous performance (AX-CPT) task where a response to the letter $\mathrm{X}$ on screen should only executed when the $\mathrm{X}$ is preceded by the letter A. It is well established that patients are impaired on 
the AX-CPT task, producing often fewer correct responses to AX sequences (impaired priming of response by a target-consistent cue) and higher rates of false alarms to BX sequences [impaired inhibition of a response prompted by a target-inconsistent cue (89)]. However, despite reports of concurrent smaller MMN and AX-CPT impairments, there appear to be no reports of a correlation between the two (90) and one explicit report of no association between the two (54).

Secondly, although NMDGluRs exhibit complex kinetics with evidence of multiple gating modes characterized by different mean open times (91-93), it is generally accepted that they mediate long duration excitatory postsynaptic currents in the brain and participate in synaptic integration and certain forms of synaptic plasticity (92). Prefrontal cortex NMDAGluRs in particular have slower kinetics than sensory regions (94) and therefore are potentially involved in maintaining activity in prefrontal neurons (95), for example during the delay periods of working memory tasks. There are reports of co-occurrence of working memory deficits and reduced MMN in patients with schizophrenia $(63,90)$ but to our knowledge, only one report of a correlation between working memory (measured using the digit sequencing task from the Japanese version of the brief assessment of cognition) and (duration) MMN in patients (96). Both classic oddball MMN amplitude (97) and longer term effects on growth in MMN amplitude (98) have been shown to correlate with digit span (the ability to maintain and or manipulate acoustic presentation of digits) in a healthy control group consistent with the requirement to store auditory information over time for both indices.

Thirdly, NMDAGluR activation leads to a cascade of events that initiate long term potentiation and depression, the primary processes responsible for new memory formation and learning in hippocampus and cortex. Retention or storage of information is less reliant on NMDAGluR. One of the most robust cognitive deficits exhibited by patients are deficits in memory (verbal declarative memory in particular) with the majority of evidence suggesting that the largest deficit, as measured by effect size, occurs for encoding or new learning of material in comparison to retention [although there is still a small deficit in retention even when initial learning differences are taken into account (99)]. Four studies report relationships between MMN and memory performance but in patients only. Baldeweg et al. (59) using a roving oddball paradigm found that the MMN trace effect (the increase in MMN that occurs with increasing repetition of prior standards) correlated with performance on an everyday memory test (Rivermead behavioral memory test). Kawakubo et al. (100) in a study that reports data on patients only found that MMN elicited by a phoneme duration deviant (but not a tone duration deviant) was correlated with immediate free recall (initial learning or encoding measure) from a list learning task, the Rey auditor verbal learning task (RAVLT). In contrast, Kaur et al. (101) found that tone duration MMN correlated with verbal memory assessed using the RAVLT in first episode psychosis patients with a schizophrenia spectrum diagnosis of either schizophrenia, schizoaffective, and schizophreniform illness. No correlations were reported for controls. Kiang et al. (84) in a standard oddball paradigm found duration MMN was correlated in patients only with short-delay as well as long delay free recall but not (significantly) with immediate free recall on another list learning task, the California verbal learning task, but neither of the free recall measures was adjusted for initial or prior learning differences. So while there is evidence of MMN correlations with memory, these correlations may not be restricted to initial learning or encoding phase.

In addition, there is evidence of relationships between MMN amplitude and other cognitive domains that are commonly shown to be impaired in patients but are less clearly dependent on NMDAGluR properties, such as executive functions [anti-saccade performance: (102); proverb interpretation: (84); perseverative errors on the Wisconsin Card Sorting Task: (103); mental control subtest of WMS-III: (85)].

In summary - MMN does not appear to be consistently related to the severity of either positive or negative symptoms experienced by the patient at the time of recording (either examined across patients or assessed within patients at different time points), consistent with (symptom) state-independence of MMN. However, MMN amplitude does appear to vary across individuals as a function of more stable features of their illness. The relationship of $\mathrm{MMN}$ to functional measures is relatively robust and there is growing evidence of correlations not only between MMN amplitude and those aspects of cognition that are likely to be reliant on unique aspects of NMDAGluR but other domains of cognition that are reliably impaired in patients such as executive functions. However, these are issues that deserve more attention and in particular, more systematic investigations are required before any strong assertions can be made about contributions from a common mechanism of NMDAGluR-dysfunction to MMN-reduction and cognitive deficits in schizophrenia.

\section{CRITERION (IV) AND (V)}

Mismatch negativity has also been investigated as a potential predictor of developing psychosis or schizophrenia in populations considered at-risk mental state (ARMS). For instance, the comprehensive assessment of at-risk mental state (CAARMS) criteria (104) defines ARMS as (1) a significant drop of global functioning over a period of 12 months and having a close biological relative with a psychotic disorder and/or (2) experiencing attenuated or very brief episodes of psychotic symptoms in combination with functional decline. MMN has been investigated in both groups; however, to date there appear to have been no MMN longitudinal studies of transition to psychosis specifically within a clinically unaffected genetic group.

Whether MMN is reduced in unaffected first-degree biological relatives of patients with schizophrenia is controversial. The initial studies by Jessen et al. (105) ${ }^{1}$ and Michie et al. (106) reported reduced oddball frequency and duration MMN respectively in first-degree relatives when compared to healthy controls, but these results with one exception were not replicated in later publications, neither for duration deviants - (72, 107-109) and (102), [based on a larger sample from the same source as (106)], nor frequency deviants - $(73,108,109)$. The one exception is (110) which interestingly used an identical MMN duration deviant paradigm as (106). While there are design and other methodological

\footnotetext{
${ }^{1}$ A somewhat puzzling result in the Jessen et al. study, is that patient MMN amplitude
} was not significantly reduced in contrast to relatives. 
differences between those studies (three in total) that show significant MMN-reductions in first-degree relatives and those that do not ( six in total), the bulk of the evidence suggests that at-risk but clinically unaffected family members do not exhibit reduced MMN (minimal support for criterion (iv) and (v) of endophenotype criteria).

The evidence that MMN is reduced in the ARMS group, is more consistent, although data on whether reduced MMN predicts transition to psychosis is still preliminary. It is important to note that while the term prodromal is sometimes used to describe those clinically defined at-risk groups (111), strictly speaking whether they are prodromal or not at the time of assessment can only be determined subsequently by whether they develop a schizophrenia spectrum disorder within the follow-up period (usually 12-24 months). All of the MMN investigations in ARMS have used duration deviants, either a duration increment (112-117), or a duration decrement $(111,118)$ or both $(112)$ but some also report data on frequency deviants in the same sample $(111,116-118)$ or a double deviant [deviant on both frequency and duration (117)]. Of these eight papers, five found that duration increment MMN was significantly reduced in the ARMS group $(112-114,116,117)$ whereas duration decrement MMN was either not significant (111, 118) or showed a smaller effect size (112). The findings for frequency MMN are mixed: (117) found that frequency MMN was reduced (as was the double deviant) but (116) did not. To date therefore, the evidence seems to suggest that deviants that differ from standards by being longer in duration are more sensitive to the at-risk mental state that other deviant types. It seems unlikely that these findings are due to the effects of medication since in each sample the numbers of ARMS individuals who were medicated with anti-psychotics at the time of testing was small as were the dosages.

Most investigations of clinical high risk groups also report transition data and examine whether MMN predicts those who will subsequently develop a schizophrenia disorder - although in two cases, the number of transitions was too small for statistical analysis $(112,113)$. Bodatsch et al. (118) were the first to report transition data. Interestingly they found that duration (decrement) $\mathrm{MMN}$ predicted those who converted to schizophrenia within a 24 month period of the assessment date whereas frequency MMN did not. Higuchi et al. (115) and Shaikh et al. (114) observed similar results for duration (increment) MMN. Neither included a frequency MMN deviant. However (117), found that the best predictor of later transition to schizophrenia was MMN to their double deviant. Neither duration alone nor frequency alone was significant. Perhaps importantly, the double deviant elicited the largest MMN (larger than that to frequency or duration alone) which perhaps reflects the importance of challenging the upper limits on MMN size in at-risk groups as well as patients with an established illness. In summary, evidence for smaller MMN within families in general is not strong but the evidence for smaller $\mathrm{MMN}$ in clinical high risk groups is quite compelling. Therefore endophenotype criterion (iv) and (v) are only partially met at best. It remains to be seen whether the reduction in the atrisk groupings is really about risk status per se or a reflection of schizophrenia-related pathology that has begun to impact on brain function.

\section{HOW DO PHARMACOLOGICAL MANIPULATIONS ALTER THE} MMN PROCESS?

Pharmacology as a field of research offers a unique avenue to study MMN both in terms of how different chemicals can perturb the perceptual inference process and how they may relate to schizophrenia pathology. When considering the pharmacological sensitivity of MMN, it is clear that a change in MMN could reflect an effect on any one of a number of constituent processes described in Section "The Measurement of MMN - Is there an Optimal Paradigm with Which to Study MMN in Schizophrenia?" Surprisingly few studies provide details on how a substance affected response to standard repetitious sounds with the majority reporting on the difference waveforms only (16/27 studies, see Tables $1-3)$. For the purpose of this review we have restricted Tables to acute drug effects on healthy adult populations. One of the key foci in pharmacological research on $\mathrm{MMN}$ is how it is affected by alterations to NMDAGluR activity (Table $\mathbf{1}$ ).

Several groups have argued that impaired plasticity linked to NMDAGluRs is a core feature of the schizophrenia illness (45, $128,129)$. The first study to demonstrate this link was actually in the macaque where Javitt and colleagues demonstrated a dose-dependent reduction in MMN following local infusion of the NMDAgluR antagonist, PCP (130). Using a flip-flop control design (see The Measurement of MMN - Is there an Optimal Paradigm with Which to Study MMN in Schizophrenia? above for description and Translation to Animal Models below for additional detail) the authors report no significant effect of phencyclidine on response to the repetitive sound (at least in these local field potentials, see Translation to Animal Models for further discussion) but a pronounced dose-dependent effect on the response to the deviant. The authors conclude that NMDAGluR activity is critical to forming the associative links between stimuli (i.e., accumulating information about transition statistics) that define the context against which a rare deviant sound is recognized as an aberrant event. Studies in humans are largely consistent with this initial study. Of eight published studies, seven report significant dose-dependent reduction of MMN amplitude after ketamine [although one only in combination with the CB1 inverse agonist rimonabant (125)]. The one exception (a low-dose study) used a selective attention paradigm in which participants were asked to attend and respond to stimuli in one ear while simultaneously hearing stimuli in the other ear (unattended) from which MMN was derived (119). Of the studies showing an effect of ketamine on MMN, four explicitly picture and/or discuss response to the repetitive standard tones with only one (120) reporting a slight but significant increase in the obligatory $\mathrm{N} 1$ component to repetitive sounds in the presence of the drug. The low-dose ketamine study by Oranje and colleagues also show enhanced N1. The most recent study reports on a roving standard paradigm demonstrating that, although MMN was reduced under ketamine overall, the effect of ketamine was more pronounced with increased repetition of the standard [i.e., when predictive confidence was highest (126)]. The paper, however, did not report on whether this pattern was due to effects on the positivity to repetitive standards or increased negativity to deviants or both. The grand-averaged (i.e., across repetitions) ERP to standards is presented in a subsequent paper reporting a DCM analysis of the same data (14). A visual 
Table 1 | N-methyl-d-aspartate receptor studies.

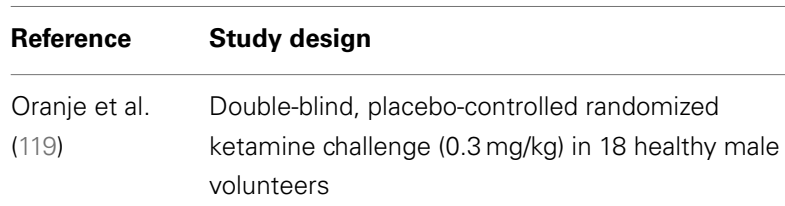

Umbricht et al. Single-blind placebo-controlled ketamine (120)

KreitschmannAndermahr et al. (121)

Umbricht et al. Single-blind, placebo-controlled psilocybin (122)

Korostenskaja et al. (123)

Heekeren et al. (124)

Schmidt et al. Double-blind, placebo-controlled ketamine (126)

Gunduz-Bruce et al. (127)

Schmidt et al. (14) recorded $70 \mathrm{~min}$ after drug administration in 18 healthy volunteers

Randomized, double-blind, placebo-controlled crossover challenge of memantine $(30 \mathrm{mg})$ in 13 healthy volunteers

Randomized, double-blind, crossover ketamine of $0.007-0.2 \mathrm{mg} / \mathrm{kg}$ and dimethyltryptamine of $0.011-0.3 \mathrm{mg} / \mathrm{kg}$ challenges, with same-day (after $2 \mathrm{~h}$ break) single-blind low and a high-dose drug administration, respectively, in 15 healthy volunteers ( 9 study participants completed both drug challenges)
Randomized, double-blind, placebo-controlled, crossover ketamine $10.5 \mathrm{mg} / \mathrm{kg} / \mathrm{h}$ following bolus of $0.24 \mathrm{mg} / \mathrm{kg}$ ) and rimonambant $(20 \mathrm{mg}$ ) challenge in 24 healthy male volunteers

Double-blind, placebo-controlled ketamine challenge $(0.006 \mathrm{mg} / \mathrm{kg} / \mathrm{min}$ following bolus of $10 \mathrm{mg}$ ) in 19 healthy volunteers and psilocybin challenge of $0.115 \mathrm{mg} / \mathrm{kg}$ in 20 healthy volunteers

\section{Double-blind, placebo-controlled ketamine} challenge (a bolus of $0.23 \mathrm{mg} / \mathrm{kg}$ over $1 \mathrm{~min}$ followed by $0.58 \mathrm{mg} / \mathrm{kg}$ for $30 \mathrm{~min}$ and then $0.29 \mathrm{mg} / \mathrm{kg}$ for $40 \mathrm{~min}$ ) with and without $\mathrm{N}$-acetylcystein co-administration (oral doses of $2000 \mathrm{mg}$ followed by $1000 \mathrm{mg} 2 \mathrm{~h}$ later) in 16 healthy volunteers

\section{Double-blind, placebo-controlled ketamine} challenge $(0.006 \mathrm{mg} / \mathrm{kg} / \mathrm{min}$ following bolus of

\section{Main findings}

Processing negativity $(\mathrm{PN})$ and $\mathrm{P} 3$

amplitude reduced and $\mathrm{N} 1$ amplitude increased with ketamine; no effects observed on MMN (frequency deviants)

N1 peak amplitude increase with ketamine; MMN (i.e., frequency and duration deviants) amplitude reduction with ketamine; MMN (i.e., duration deviants) peak amplitude latency increase with ketamine

Ketamine affected MMF latency and dipole moment due to effects on deviants (frequency, duration, and intensity); no effect on N1

N1 peak amplitude reduction with psilocybin; no effect on P2 $10 \mathrm{mg}$ ) in 19 healthy volunteers (17 subjects entered the final dynamic causal modeling analysis)
No effect of ketamine alone on MMN amplitudes (i.e., frequency and duration deviants); addition of rimonambant resulted in $\mathrm{MMN}$ amplitude reduction

Reduced frontal MMN with ketamine with increasing number of standards with psilocybin

MMN amplitude reduced for intensity and frequency deviants but not duration deviants; $\mathrm{N}$-acetylcystein did not alter the impact of ketamine on MMN

Ketamine selectively reduced synaptic plasticity in the forward connection from the left primary auditory cortex (A1) to the left superior temporal gyrus along with MMN amplitude reduction (roving paradigm); no effect on MMN

\section{Comments}

Ketamine did not affect error rate and reaction time in selective attention task; dose lower than in studies showing an effect on MMN; study reported ERPs in response to standard stimuli

MMN topography was not altered by ketamine; study did not report ERPs in response to standard stimuli

Ketamine reduced mean global field power for MMF; study reported ERPs in response to standard stimuli

Non-significant trend toward smaller MMN amplitudes for frequency deviants with psilocybin; study did not report ERPs in response to standard stimuli

No effect on MEG derived measures of MMN, P1 and N1; study did not report ERPs in response to standard stimuli

Subjects performed a continuous performance task was performed whilst EEG was recorded; study reported ERPs in response to standard stimuli

Ketamine dose lower than in studies showing an effect on MMN; study did not report ERPs in response to standard stimuli

Placebo MMN amplitudes correlated with severity of cognitive impairment induced by ketamine; study did not report ERPs in response to standard stimuli

MMN recorded with multi-deviant paradigm; study did not report ERPs in response to standard stimuli

Ketamine effects on synaptic plasticity correlated significantly with ratings of ketamine-induced cognitive impairments; study reported ERPs in response to standard stimuli 
Table 2 | Nicotine receptor studies.

\begin{tabular}{|c|c|c|c|}
\hline Reference & Study design & Main findings & Comments \\
\hline $\begin{array}{l}\text { Harkrider and } \\
\text { Hedrick (137) }\end{array}$ & $\begin{array}{l}\text { Single-blind placebo-controlled nicotine challenge in } \\
10 \text { smokers ( } 21 \mathrm{mg} / \text { day) and } 4 \text { non-smokers ( } 7 \mathrm{mg} / \text { day) }\end{array}$ & $\begin{array}{l}\text { Larger } \mathrm{MMN} \text { area and steeper slope in } \\
\text { response to deviant stimuli }\end{array}$ & $\begin{array}{l}\text { Small and heterogeneous } \\
\text { sample; study reported ERPs in } \\
\text { response to standard stimuli }\end{array}$ \\
\hline $\begin{array}{l}\text { Inami et al. } \\
(142)\end{array}$ & $\begin{array}{l}\text { Counterbalanced placebo versus nicotine } \\
\text { administration (equivalent to } 16.1 \pm 2.7 \mathrm{mg} / \text { day) } 10 \\
\text { healthy non-smokers ( } 5 \text { males) }\end{array}$ & Nicotine shortened MMN peak latency & $\begin{array}{l}\text { Small sample size; study } \\
\text { reported ERPs in response to } \\
\text { standard stimuli }\end{array}$ \\
\hline $\begin{array}{l}\text { Baldeweg } \\
\text { et al. (138) }\end{array}$ & $\begin{array}{l}\text { Randomized placebo-controlled nicotine challenge } \\
(2 \mathrm{mg}) \text { in } 20 \text { healthy smokers }\end{array}$ & $\begin{array}{l}\text { Nicotine increased MMN amplitude } \\
\text { mainly by affecting response to } \\
\text { standard stimuli (no change in } \\
\text { response to deviant stimuli) }\end{array}$ & $\begin{array}{l}\text { Nicotine enhanced repetition } \\
\text { positivity; study reported ERPs in } \\
\text { response to standard stimuli }\end{array}$ \\
\hline $\begin{array}{l}\text { Knott et al. } \\
\text { (143) }\end{array}$ & $\begin{array}{l}\text { Nicotine challenge ( } 6 \mathrm{mg} \text { single dose) in } 14 \text { healthy } \\
\text { non-smokers }\end{array}$ & $\begin{array}{l}\text { No effect on MMN (frequency } \\
\text { deviants) }\end{array}$ & $\begin{array}{l}\text { Study did not report ERPs in } \\
\text { response to standard stimuli }\end{array}$ \\
\hline $\begin{array}{l}\text { Dunbar et al. } \\
\text { (139) }\end{array}$ & $\begin{array}{l}\text { Randomized and placebo-controlled challenge with } \\
\text { oral nicotine agonist AZD3480 (ascending doses from } \\
2 \text { to } 320 \mathrm{mg} \text { ) in } 48 \text { healthy subject and in } 24 \text { subject } \\
\text { receiving repeatedly constant oral dose or placebo }\end{array}$ & $\begin{array}{l}\text { Increased MMN amplitude with } \\
\text { reduced latency after } 10 \text { days of } \\
\text { consecutive agonist administration } \\
\text { and/or single dose of } 200 \mathrm{mg}\end{array}$ & $\begin{array}{l}\text { Study did not report ERPs in } \\
\text { response to standard stimuli }\end{array}$ \\
\hline $\begin{array}{l}\text { Martin et al. } \\
(141)\end{array}$ & $\begin{array}{l}\text { Single-blind, placebo-controlled nicotine challenge } \\
\text { ( } 4 \mathrm{mg} \text { ) in } 11 \text { non-smokers and } 9 \text { smokers (following } 2 \mathrm{~h} \\
\text { nicotine abstinence) }\end{array}$ & $\begin{array}{l}\text { Increased } \mathrm{MMN} \text { amplitude in response } \\
\text { to nicotine without affecting } \mathrm{N} 1 \text { and } \\
\text { ERPs in response to standard stimuli }\end{array}$ & $\begin{array}{l}\text { Study reported ERPs in response } \\
\text { to standard stimuli }\end{array}$ \\
\hline $\begin{array}{l}\text { Knott et al. } \\
(140)\end{array}$ & $\begin{array}{l}\text { Randomized double-blind, placebo-controlled } \\
\text { crossover nicotine challenge }(6 \mathrm{mg}) \text { in } 21 \text { non-smokers } \\
\text { (11 males) }\end{array}$ & $\begin{array}{l}\text { Drug by gender interaction of } \\
\text { non-significant MMN amplitude } \\
\text { increase in females and non-significant } \\
\text { MMN amplitude decrease in males }\end{array}$ & $\begin{array}{l}\text { Study reported ERPs in response } \\
\text { to standard stimuli }\end{array}$ \\
\hline
\end{tabular}

comparison of Figure 1 (placebo) and Figure 2 (ketamine) from the paper suggests that the effect of ketamine on MMN was perhaps a combination of reduced positivity in the standard waveform and reduced negativity in response to the deviant. However, DCM analyses applied to the data indicated the ketamine had a selective effect on parameters representing synaptic plasticity with no effect on indices reflecting adaptation. Additionally, analysis indicated that the major effect of ketamine was to reduce the normal increase in synaptic plasticity in the forward connection between left A1 and left STG in response to the deviant tones. Therefore while ketamine administration and schizophrenia are both associated with reduced MMN, the pattern of change (at least for this roving paradigm) is quite distinct. Ketamine-induced a prominent change in feed-forward connections between A1 and STG only (14) while schizophrenia was associated principally with reduced intrinsic connections within $\mathrm{A} 1$ and significant alteration in prefrontal-STG connections (60).

In Schmidt et al. $(14,126)$, and an earlier observation by Umbricht and colleagues (131), MMN measures were associated with the intensity of psychotic-like reactions to ketamine. Schmidt et al. (126) reported that participants with the most restricted growth in MMN with increased standard repetition experienced the most pronounced disturbances noted on a "control and cognition" subscale of the altered state of consciousness questionnaire in the presence of ketamine. Similarly Umbricht and colleagues observed that the participants who produced the smallest MMNs at baseline experienced the highest symptom ratings (on a variety of measures) under ketamine. In the subsequent DCM analysis of Schmidt et al. (14), those who experienced the most pronounced "control and cognition" subscale disturbances in the presence of ketamine also showed the most pronounced decrease in plasticity in the left A1-STG connections under ketamine. Although the measures differ between studies, these observations invite the intriguing conclusion that small MMN amplitude (and/or limited growth in $\mathrm{MMN}$ ) may indicate a limitation in synaptic plasticity that is linked to vulnerability to psychotic-like phenomena. Interestingly, this vulnerability does not appear to be generic as studies have shown no relationship between MMN amplitude and psychotic-like response to psilocybin and no significant effect of psilocybin on MMN amplitude $(122,126)$. Furthermore, there is evidence that this effect on NMDAGluR-mediated plasticity shows some specificity to ketamine-induced antagonism. Memantine (also an NMDAGluR antagonist) actually augmented MMN amplitude (123). The downstream effect of ketamine (and MK-801) has recently been demonstrated to be quite different to that of memantine. One interesting observation is that these compounds have opposing effects on postsynaptic density proteins - namely ketamine and MK-801 reliably increased Homer1a relative to Homer $1 b$ expression while memantine has the reverse effect. Authors suggest that the former impacts the expression of genes related to response to neuronal injury and preservation of homeostatic scaling of synaptic response. The latter, in contrast, 
Table 3 | Monoamine receptor studies.

\begin{tabular}{|c|c|c|c|}
\hline Reference & Study design & Main findings & Comments \\
\hline $\begin{array}{l}\text { Mervaala } \\
\text { et al. (157) }\end{array}$ & $\begin{array}{l}\text { Noradrenaline challenge with alpha 2-antagonist } \\
\text { atipamezole }(0.1 \mathrm{mg} / \mathrm{kg}) \text { in six healthy male } \\
\text { volunteers }\end{array}$ & $\begin{array}{l}\text { Reduced P3 amplitude without affecting } \\
\text { MMN and Nd; improved digit span and } \\
\text { word recognition performance }\end{array}$ & $\begin{array}{l}\text { Small sample size; study did not } \\
\text { report ERPs in response to standaro } \\
\text { stimuli }\end{array}$ \\
\hline $\begin{array}{l}\text { Schreiber } \\
\text { et al. (158) }\end{array}$ & $\begin{array}{l}\text { Double-blind, placebo-controlled crossover } \\
\text { administration of ceruletide }(0.5 \text { and } 2.5 \mathrm{mg}) \text { in } 13 \\
\text { healthy volunteers }\end{array}$ & $\begin{array}{l}\text { No effect on MMN; PN larger with } \\
\text { ceruletide }\end{array}$ & $\begin{array}{l}\text { Study did not report ERPs in } \\
\text { response to standard stimuli }\end{array}$ \\
\hline $\begin{array}{l}\text { Kahkonen } \\
\text { et al. (159) }\end{array}$ & $\begin{array}{l}\text { Placebo-controlled haloperidol challenge }(2 \mathrm{mg}) \text { in } \\
12 \text { healthy volunteers }\end{array}$ & $\begin{array}{l}\text { MMN increased with haloperidol } \\
\text { without affecting other ERP components }\end{array}$ & $\begin{array}{l}\text { MEG measures were unaffected; } \\
\text { study reported ERPs in response to } \\
\text { standard stimuli }\end{array}$ \\
\hline $\begin{array}{l}\text { Pekkonen } \\
\text { et al. (160) }\end{array}$ & Haloperidol challenge 2 mg in 12 healthy volunteers & No effect on MMN & $\begin{array}{l}\text { Study reported ERPs in response to } \\
\text { standard stimuli }\end{array}$ \\
\hline $\begin{array}{l}\text { Ahveninen } \\
\text { et al. (161) }\end{array}$ & $\begin{array}{l}5 \mathrm{HT} \text { challenge using acute tryptophan depletion } \\
\text { versus placebo control in } 13 \text { healthy volunteers }\end{array}$ & Delayed MMN latency & $\begin{array}{l}\text { Study reported ERPs in response to } \\
\text { standard stimuli }\end{array}$ \\
\hline $\begin{array}{l}\text { Umbricht } \\
\text { et al. (131) }\end{array}$ & $\begin{array}{l}\text { Single-blind, placebo-controlled psilocybin } \\
\text { challenge }(0.28 \mathrm{mg} / \mathrm{kg}) \text { in } 18 \text { healthy volunteers and } \\
\text { ketamine }(0.9 \mathrm{mg} / \mathrm{kg} / \mathrm{h}) \text { in } 20 \text { healthy volunteers } \\
\text { whilst performing a continuous performance task }\end{array}$ & $\begin{array}{l}\text { Smaller MMN to frequency and duration } \\
\text { deviants was correlated with stronger } \\
\text { effects on the brief psychiatric rating } \\
\text { scale during ketamine but not psilocybin }\end{array}$ & $\begin{array}{l}\text { Study does not report MMN in the } \\
\text { respective placebo conditions and } \\
\text { did not report ERPs in response to } \\
\text { standard stimuli }\end{array}$ \\
\hline $\begin{array}{l}\text { Leung et al. } \\
\text { (162) }\end{array}$ & $\begin{array}{l}\text { Double-blind, placebo-controlled crossover } \\
\text { administration of bromocriptine }(2.5 \mathrm{mg}) \text { or } \\
\text { pergolide }(0.1 \mathrm{mg}) \text { in } 15 \text { healthy volunteers }\end{array}$ & No effect on MMN, P1, N1, N2, and P3 & $\begin{array}{l}\text { Study reported ERPs in response to } \\
\text { standard stimuli }\end{array}$ \\
\hline $\begin{array}{l}\text { Korostenskaja } \\
\text { et al. (163) }\end{array}$ & $\begin{array}{l}\text { Double-blind, placebo-controlled crossover } \\
\text { administration of methylphenidate challenge } \\
(40 \mathrm{mg}) \text { in } 13 \text { healthy volunteers }\end{array}$ & $\begin{array}{l}\text { No effect on } \mathrm{MMN} \text { or } \mathrm{N} 1 \text {; } \mathrm{P} 2 \text { amplitude } \\
\text { reduction with methylphenidate }\end{array}$ & $\begin{array}{l}\text { Study reported ERPs in response to } \\
\text { standard stimuli }\end{array}$ \\
\hline $\begin{array}{l}\text { Leung et al. } \\
\text { (164) }\end{array}$ & $\begin{array}{l}\text { Double-blind, placebo-controlled crossover design } \\
\text { following tyrosine/phenylalanine and/or tyrosine } \\
\text { depletion intervention in } 16 \text { healthy volunteers }\end{array}$ & No effects on ERPs & $\begin{array}{l}\text { Study reported ERPs in response to } \\
\text { standard stimuli }\end{array}$ \\
\hline
\end{tabular}

strengthens synaptic transmission. These very different effects on plasticity may go some way to explaining the opposing effects of these NMDAGluR-antagonists on MMN and invite speculation as to whether individual differences in these same ratios may in fact confer differential susceptibility to ketamine-induced psychoticlike experiences (and disruption to the MMN process, however see also discussion of animal research using memantine in Section "Translation to Animal Models"). In summary, antagonism of NMDAGluRs in the presence of ketamine produces quite consistent reduction in MMN amplitudes and continues to hold promise in furthering our understanding of the plasticity underlying MMN as well as vulnerability to psychotic phenomena. Of course it should be remembered that acute disruption under ketamine is unlikely to mirror the full consequences of adjustment to a more chronic compromise in function (if present) in schizophrenia.

Just as there are multiple elements to the MMN process, there are multiple ways to pharmacologically influence NMDAGluRmediated synaptic plasticity [for a relevant review see Ref. (132)]. NMDAGluR antagonism also occurs under acute exposure to alcohol and consistent with this, acute administration of ethanol has been shown to reduce MMN amplitude $(133,134)$. Nicotine in contrast enhances synaptic plasticity with mechanisms linked to effects on presynaptic NMDAGluRs (135). Nicotine exerts its effects on the central nervous system via acetylcholine receptors (135). Galantamine has been used to test theories about how augmentation of cholinergic neurotransmission can modulate gain in MMN (136). The results of both an empirical study and a simulation experiment indicate that enhanced cholinergic neurotransmission alters precision in prediction-modeling - i.e., changes confidence in the current inference model. More specifically, under these conditions the system places a greater emphasis on bottom-up input and "boosts" the response to deviants while also attenuating the usual reduction in confidence in a model following the occurrence of a deviance. The authors suggest that acetylcholine plays a key role in modulating gain in superficial pyramidal neurons in early sensory brain areas. Consistent with this action, five of the seven studies listed in Table 2 support nicotine enhancement of MMN. Significant enhancement of MMN has been demonstrated under both acute (137-141) and more prolonged exposure (139). Of the seven studies listed, five present or report on response to standard tones but only one indicates significant drug effects. Baldeweg et al. employed the roving standard paradigm and revealed that the increase in MMN amplitude with nicotine was due to a selective augmentation of the positivity 
to repeated standards with no significant effect on response to deviants.

Cannabis use is considered by some to be a risk factor in the development of psychosis. Furthermore, chronic cannabis use has been associated with gray matter volume changes and cognitive deficits reminiscent of those in schizophrenia (144-147). The action of endogenous cannabanoids is also linked to NMDAGluRs in protecting against excessive stimulation at glutamatergic synapses. The cannabanoids are released from postsynaptic neurons and exert their action on $\mathrm{CB} 1$ receptors located on presynaptic neurons which transiently decreases neurotransmitter release [(148) for review]. There are currently two published studies on the acute effects of cannabis [in fact the latter is a reanalysis of the former with genetic data included $(149,150)]$. The first of these explored the effect of administering $\Delta$ 9-tetrahydrocannabinol (THC) alone (the psychoactive component of cannabis) versus in combination with the other cannabinoids present in cannabis extract. The results indicated no significant impact of $\triangle 9$-THC alone, but significant augmentation of MMN at central sites in the presence of cannabis extract compared to placebo. However the study also demonstrated a significant correlation such that higher concentration of the $\Delta 9$ THC-metabolite 11-OH-THC was associated with smaller MMN amplitude $(r=0.62, p=0.002)$. In their later combination with genetic data the same group revealed that susceptibility to MMNreduction in the presence of $\triangle 9-\mathrm{THC}$ was a function of genotype for neuregulin 1 (MMN reduced in the presence of $\triangle 9$-THC for those with NRG1 rs7834206 polymorphism). Neuregulin 1 is a gene implicated in schizophrenia that influences synaptic plasticity via multiple pathways, including those involving NMDAGluRs (128). The possibility that genes confer vulnerability to $\Delta 9$ THC effects on cognitive processing also finds support in animal research where heterozygous Neuregulin 1 knockout mice have been observed to show differential sensitivity to the acute effects of $\triangle 9$-THC on behavioral phenotypes of schizophrenia (151).

Despite dopamine being a modulator of NMDAGluRs and a central focus of treatment and models of schizophrenia (37, 132), there are no studies supporting a significant effect of altered dopamine levels on MMN amplitude in healthy adults (see Table 3). Furthermore, with one recent exception (reviewed below), studies within schizophrenia do not support a significant effect of medication type or dose on MMN [see Ref. (5) for review], and no significant differences in MMN amplitude between medicated and unmedicated patients $(52,152)$. However, Zhou and colleagues (79) have recently reported a significant progressive increment in $\mathrm{MMN}$ in persons with schizophrenia treated with aripiprazole (larger at 4 and 8 weeks of treatment than at baseline). MMN was measured using a traditional oddball paradigm with two deviant types (frequency and duration) and effects are presented and reported for the difference waveforms only. Aripiprazole differs from other second generation anti-psychotics in that its action at dopamine D2 receptors shows functional selectivity (153-155). It has been proposed that this selectivity may be related to observations that it has differential effects on the two main dopaminergic pathways, namely a predominant effect on the mesolimbic pathway (156). Although MMN remained significantly smaller than that in matched controls, the authors argue that the effect of the drug treatment on MMN does raise questions about whether MMN amplitude is really a trait or state marker. Finally studies on benzodiazepines, often prescribed to persons with schizophrenia, have consistently failed to demonstrate any effect on MMN amplitude (see Table 3).

In summary, the literature to date on the pharmacology of MMN generally reflects its obvious relationship with experience-dependent synaptic plasticity. The observed effects of ketamine, nicotine and cannabis provide support for the NMDAGluR-susceptibility of the system underlying MMN and therefore utility to schizophrenia research on $\mathrm{MMN}$ as they offer useful insights into the neurobiological processes that can influence or modulate MMN amplitude. However the memantine studies clearly caution that the relationship between perturbation of NMDAGluRs and MMN amplitude is not a simple one. There is insufficient information within most published studies to determine exactly how the various agents are altering the underlying processes with most reporting on difference waveforms only. Clarity regarding which elements of changed responsiveness are affected by drugs is particularly important to a thorough understanding of the process and these issues are discussed further in Section "Translation to Animal Models" below. Where possible it may be advantageous to add genotyping to pharmacology studies as it is well known that susceptibility to drug effects can be dependent on genetic profiles but of course the cost and sample size requirements are often prohibitive.

\section{TRANSLATION TO ANIMAL MODELS}

Animal models have the potential to inform investigation of the physiological basis of MMN and potentially how it is disrupted in persons with schizophrenia. However, the primary issue of debate in animal models of MMN is to determine which components of the MMN process can be observed (and under which conditions they can be observed) in animals, there being some skepticism expressed in the past over whether the rodent brain exhibits "true MMN" (165). Debate over how exactly to measure MMN (see The Measurement of MMN - Is there an Optimal Paradigm with Which to Study MMN in Schizophrenia?) is therefore particularly relevant to animal work. Results from several different control designs are reviewed in this section and for ease of communication they are presented diagrammatically in Figure $\mathbf{1}$.

The presence of adaptation to repeated stimuli (or stimulusspecific adaptation, SSA) in A1 is well-described in the cat $(8,166)$, rat (167-170), and macaque (171). A1 neuron populations will adapt to repetitive stimuli and will exhibit relatively large responses to a rare deviant compared to a common standard. However, as reviewed in Section "The Measurement of MMN - Is there an Optimal Paradigm with Which to Study MMN in Schizophrenia?" evidence of "true MMN" must include something more than just adaptation effects. Terminology used is not consistent across animal and human studies so for simplicity we adopt the following nomenclature: oddball mismatch response (MMR) is used when referring to the difference between the response to a rare deviation and the regular (usually physically different) repeating sound; and controlled MMR is used to define evidence of contextual deviance detection when a study has included some kind of control for adaptation and physical characteristics of the stimuli (see Figure 1). 


\section{A Oddball sequences - flip-flop design}

Ascending

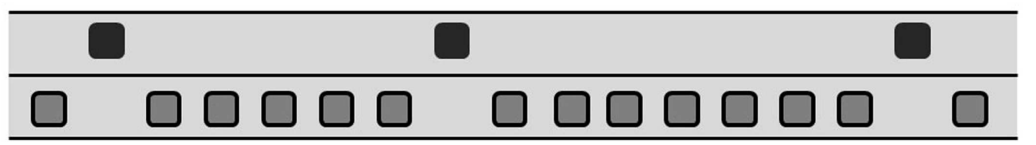

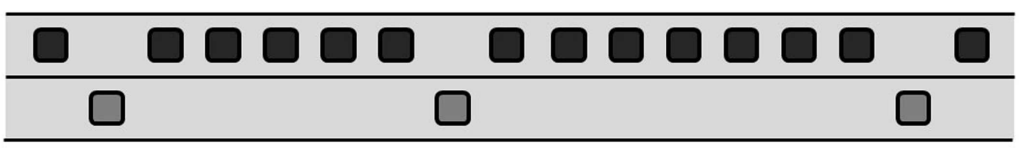

\section{B Control sequences - deviant-alone design}

Ascending

\begin{tabular}{lll}
\hline$\square$ & $\square$ & $\square$ \\
\hline
\end{tabular}

Descending
Presentation rate (p)

0.125

\section{c Control sequences - many standards design}

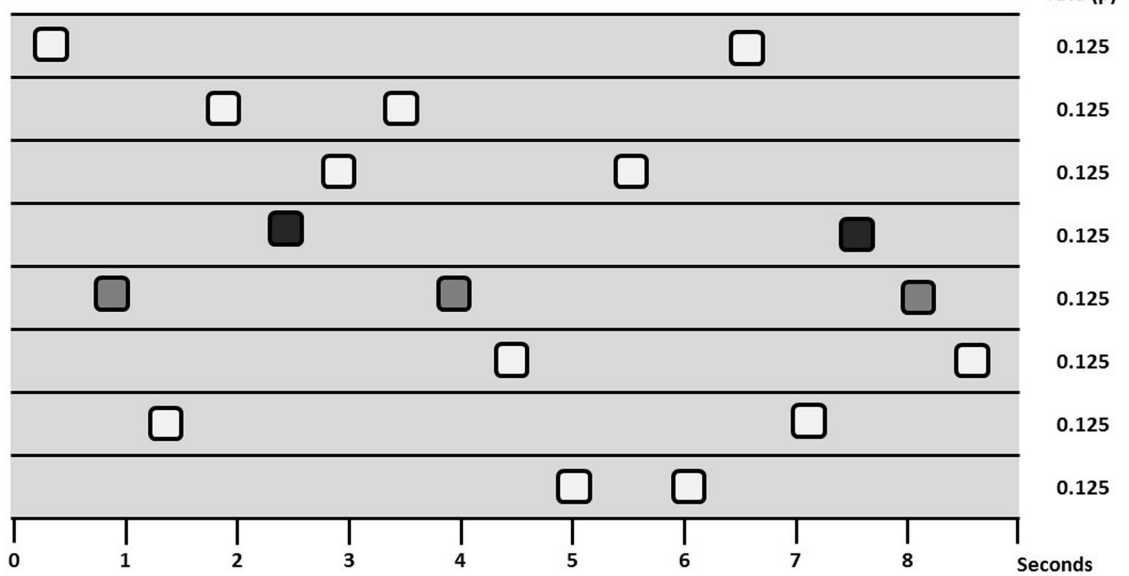

FIGURE 1 | Schematic of sequence design showing sequences with deviants presented at a probability of 0.125 (1/8), two oddball sequences are presented in a flip-flop design (A), controlling for the physical characteristics of the stimuli. Differential adaptation can be controlled for through the use of a deviant-alone control (B), which presents the deviant at the same temporal rate as it is presented in the oddball sequence, but without the intervening standards; or the many-standards control (C), which presents several stimuli (including the deviant) at the same temporal rate as the oddball sequences.

\section{WHAT IS THE EVIDENCE FOR A “CONTROLLED MMR" IN LOCAL FIELD POTENTIALS?}

Table 4 summarizes the animal studies that utilize oddball paradigms to test for evidence that a contextually deviant sound has been detected. The location of the recording electrode plays a large role in the findings of these studies, as epidural-placed electrodes receive input from a larger and more distributed network of cortical neurons than local field potential electrodes (LFP; measuring changes in synaptic potentials) or electrodes that register multi- or single-unit spike activity [MUA, SUA; see Ref. (165)]. The majority of studies using LFP recordings have searched for evidence of contextual deviance detection by recording from $\mathrm{A} 1$, but some also have recorded from the hippocampus (172-174). The majority of investigations using LFP or MUA 
Table 4 | Summary of papers investigating mismatch responses in animal models.

\begin{tabular}{|c|c|c|c|c|c|c|c|}
\hline Reference & Species/strain & $\begin{array}{l}\text { Recording } \\
\text { type/location }\end{array}$ & Anesthesia & Control type & $\begin{array}{l}\text { Oddball } \\
\text { MMR } \\
\text { finding }\end{array}$ & $\begin{array}{l}\text { Controlled } \\
\text { MMR } \\
\text { finding }\end{array}$ & $\begin{array}{l}\text { Effects of NMDAGluR } \\
\text { antagonism }\end{array}$ \\
\hline $\begin{array}{l}\text { Ulanovsky et al. } \\
\text { (8) }\end{array}$ & Cat & $\begin{array}{l}\text { MUA in } \mathrm{A} 1 \text { and } \\
\mathrm{MGB}\end{array}$ & $\begin{array}{l}\text { Xylazine/ } \\
\text { ketamine }\end{array}$ & None & Yes & N/A & \\
\hline $\begin{array}{l}\text { Fishman and } \\
\text { Steinschneider } \\
\text { (171) }\end{array}$ & Cat & LFP in A1 & Awake & Many-standards & Yes & No & \\
\hline Javitt et al. (130) & Macaque & LFP in A1 & Awake & None & Yes & N/A & $\begin{array}{l}\text { Infusions of PCP ( } 5 \text { and } 10 \mu \mathrm{g} \text { ) } \\
\text { into the auditory cortex } \\
\text { reduced oddball MMR }\end{array}$ \\
\hline $\begin{array}{l}\text { Ehrlichman et al. } \\
\text { (173) }\end{array}$ & $\begin{array}{l}\text { Mouse } \\
\text { (C57/129Sv } \\
\text { background) }\end{array}$ & LFP in CA3 & Awake & None & Yes & N/A & \\
\hline Farley et al. (169) & $\begin{array}{l}\text { Rat (unknown } \\
\text { strain) }\end{array}$ & $\begin{array}{l}\text { LFP and MUA in } \\
\text { A1 }\end{array}$ & Awake & Many-standards & Yes & No & \\
\hline $\begin{array}{l}\text { Eriksson and Villa } \\
\text { (167) }\end{array}$ & Rat (Long-Evans) & LFP in A1 & Awake & Deviant-alone & Yes & No & \\
\hline Imada et al. (175) & Rat (Long-Evans) & $\begin{array}{l}\text { LFP in frontal and } \\
\text { parietal cortices }\end{array}$ & Awake & $\begin{array}{l}\text { Deviant-alone, } \\
\text { standard-alone }\end{array}$ & Yes & Yes & \\
\hline Pincze et al. (176) & Cat & Epidural above A1 & Awake & None & Yes & N/A & \\
\hline $\begin{array}{l}\text { Umbricht et al. } \\
\text { (177) }\end{array}$ & Mouse (C57/129) & Epidural above A1 & Awake & Deviant-alone & Yes & No & \\
\hline Jung et al. (178) & $\begin{array}{l}\text { Rat (black } \\
\text { hooded) }\end{array}$ & Epidural above A1 & Awake & Many-standards & Yes & Yes & \\
\hline $\begin{array}{l}\text { Tikhonravov et al. } \\
\text { (179) }\end{array}$ & $\begin{array}{l}\text { Rat (Hannover- } \\
\text { Wistar) }\end{array}$ & Epidural near A1 & $\begin{array}{l}\text { Pentobarbital } \\
\text { sodium }\end{array}$ & Deviant-alone & Yes & Yes & $\begin{array}{l}\text { High-dose }(0.3 \mathrm{mg} / \mathrm{kg}) \text {, but not } \\
\text { low-dose }(0.1 \mathrm{mg} / \mathrm{kg}) \mathrm{MK}-801 \\
\text { reduced oddball MMR }\end{array}$ \\
\hline $\begin{array}{l}\text { Tikhonravov et al. } \\
\text { (180) }\end{array}$ & $\begin{array}{l}\text { Rat (Hannover- } \\
\text { Wistar) }\end{array}$ & Epidural near A1 & $\begin{array}{l}\text { Pentobarbital } \\
\text { sodium }\end{array}$ & Deviant-alone & Yes & Yes & $\begin{array}{l}\text { Low-dose }(3 \mathrm{mg} / \mathrm{kg}) \\
\text { memantine increased oddball } \\
\text { MMR, high-dose }(10 \mathrm{mg} / \mathrm{kg}) \\
\text { reduced oddball MMR }\end{array}$ \\
\hline Roger et al. (181) & Rat (Long-Evans) & $\begin{array}{l}\text { Epidural above } \\
\text { motor, parietal } \\
\text { and anterior } \\
\text { cingulate cortices }\end{array}$ & Awake & None & Yes & N/A & \\
\hline
\end{tabular}


Table 4 | Continued

\begin{tabular}{|c|c|c|c|c|c|c|c|}
\hline Reference & Species/strain & $\begin{array}{l}\text { Recording } \\
\text { type/location }\end{array}$ & Anesthesia & Control type & $\begin{array}{l}\text { Oddball } \\
\text { MMR } \\
\text { finding }\end{array}$ & $\begin{array}{l}\text { Controlled } \\
\text { MMR } \\
\text { finding }\end{array}$ & $\begin{array}{l}\text { Effects of NMDAGluR } \\
\text { antagonism }\end{array}$ \\
\hline Ahmed et al. (182) & $\begin{array}{l}\text { Rat (Sprague- } \\
\text { Dawley) }\end{array}$ & Epidural above A1 & Urethane & Many-Standards & Yes & Yes & \\
\hline $\begin{array}{l}\text { Astikainen et al. } \\
\text { (183) }\end{array}$ & $\begin{array}{l}\text { Rat (Sprague- } \\
\text { Dawley) }\end{array}$ & Epidural above A1 & Urethane & Many-Standards & Yes & Yes & \\
\hline $\begin{array}{l}\text { Lazar and } \\
\text { Metherate (184) }\end{array}$ & $\begin{array}{l}\text { Rat (Sprague- } \\
\text { Dawley) }\end{array}$ & Epidural above A1 & $\begin{array}{l}\text { Urethane/ } \\
\text { xylazine }\end{array}$ & Deviant-alone & Yes & No & \\
\hline $\begin{array}{l}\text { Ruusuvirta et al. } \\
\text { (174) }\end{array}$ & $\begin{array}{l}\text { Rat (Sprague- } \\
\text { Dawley) }\end{array}$ & $\begin{array}{l}\text { Epidural above } \\
\text { A1/LFP in } \\
\text { subiculum, DG, } \\
\text { CA1 }\end{array}$ & Urethane & None & Yes & $\mathrm{N} / \mathrm{A}$ & \\
\hline $\begin{array}{l}\text { Astikainen et al. } \\
\text { (185) }\end{array}$ & Rat (Wistar) & Epidural above A1 & Urethane & None & Yes & $\mathrm{N} / \mathrm{A}$ & \\
\hline $\begin{array}{l}\text { Nakamura et al. } \\
\text { (186) }\end{array}$ & Rat (Wistar) & Epidural near A1 & Awake & Many-Standards & Yes & Yes & \\
\hline $\begin{array}{l}\text { Ruusuvirta et al. } \\
\text { (187) }\end{array}$ & Rat (Wistar) & Epidural above A1 & Urethane & Deviant-alone & Yes & Yes & \\
\hline $\begin{array}{l}\text { Ruusuvirta et al. } \\
\text { (188) }\end{array}$ & Rat (Wistar) & Epidural above A1 & Urethane & None & Yes & N/A & \\
\hline
\end{tabular}

A1, primary auditory cortex; CA1, CA1 region of hippocampus; DG, dentate gyrus; LFP, local field potentials; MGB, medial geniculate body of thalamus; MUA, multi-unit activity; SUA, single-unit activity.

(intra-cortical recordings), that also use many-standards or deviant-alone control, have not found any evidence for true MMR in the A1 $(8,167,169,171)$, whereas the majority of studies using epidural recordings and appropriate controls have found evidence for contextual deviance detection. This indicates that while adaptation to stimulus frequency/pitch does occur in the $\mathrm{A} 1$, the deviance-detection component of the MMN has not been identified in this region, and if it is present in the A1, it may be generated by more distributed networks than can only be observed using LFP recordings.

One of the first animal model studies (130) found larger responses to deviant sounds in an oddball paradigm originate in the supragranular layers (II-III) and are dependent upon normal functioning of the NMDAGluR (covered in Section "How do Pharmacological Manipulations Alter the MMN Process?"). However, Javitt et al. did not utilize a many-standard control and in a more recent study that did (171), larger responses were not observed to the deviant compared to the same tone in the many-standards sequence (no evidence of true MMR). The many-standards control in this study may have overestimated adaptation, however, as the deviant was presented at a probability of $10 \%$ in the oddball sequence, and the tones used for the many-standards control were presented at a maximum rate of 5\% (171).

There are, to our knowledge, only two studies thus far utilizing LFP recording that have found some evidence for what might be considered controlled MMR in the rat brain $(170,175)$. Imada et al. (175), using a frequency deviant paradigm, found that the difference between the ERPs to deviant and standard stimuli was significantly elevated from 0 in an oddball MMR. However as a control they included separate sequences preserving the timing of standard sounds (without deviants) and deviant sounds (without standards) from the original oddball sequence. The ERP to deviant-alone and the standard-alone did not differ (175). According to the authors, this indicates that there was a statistically significant change in the response to the deviant stimuli in the oddball measure, over and above adaptation, which may hint at the presence of true MMR, albeit one that is not large enough to produce a statistically significant difference in responses to the oddball deviant compared to the deviant-alone. Taaseh et al. (170) utilized both LFP and MUA recording and found that the response to the oddball deviant tones did not exceed the response to the same tone in a many-standards control sequence (their diversebroad sequence). However, the response to the deviant sound was larger than the many-standards control in some recordings (although not at a population level), indicating that perhaps a subset of neurons do exhibit sensitivity to the contextual deviance of the sound (170). In addition, their thorough characterization of adaptation effects was used to generate a model which predicted that if only adaptation were occurring, the response to the deviant would be smaller than the response to the same tone in the many-standards control. However, these responses did not differ significantly, suggesting (albeit rather indirectly) that contextual 
deviance detection is occurring in the auditory cortex. There is therefore some evidence that recognition of contextual deviance occurs in the rat A1. Such hints of response to contextual aberrance may represent the first step in a cascade that results in full MMN responses (170). This study, however, did not identify the significantly elevated response to the deviant compared to the control that is similar to the MMN typically seen in humans- a pattern only observed in animal models when recorded from larger brain volumes (165).

\section{WHAT IS THE EVIDENCE FOR A “CONTROLLED MMR” IN EPIDURAL RECORDINGS?}

Studies using epidural recordings in animals (mainly rats) use electrodes implanted in the skull or sitting on the dura over the auditory cortex (or close to the auditory cortex) to record ERPs elicited during oddball sequences. Table 2 summarizes these studies. Of these, four use the many-standards control. Ahmed et al. (182) used speech sounds as stimuli, and found larger responses to the deviant sound/ba/in an oddball sequence compared to the same sound presented at the same rate in a many-standards control in anesthetized rats (182). Nakamura et al. (186) and Jung et al. (178) both investigated responses to frequency/pitch deviants in awake rats, and found larger responses to deviant stimuli compared to those in the many-standards control sequence $(178,186)$. Astikainen et al. (183) examined responses to frequency deviants in anesthetized rats and found evidence of deviance detection when the deviant was a high frequency $(4.2 \mathrm{kHz})$ stimulus, not a low frequency stimulus $(3.8 \mathrm{kHz})$, as was also found in Nakamura et al. (3.6 Vs. $2.5 \mathrm{kHz}$ ) (183). Nakamura et al. also investigated the effect of duration deviants and identified larger responses to long (but not short) duration deviants compared to the same tones in the many-standards control sequence (186). Therefore all four studies using the many-standards control have indeed observed a response reminiscent of controlled MMR.

Although all these studies all report deviance detection in the rat brain, the morphology of the ERPs differs between each of the studies, with the most dramatic difference in ERPs being observed between the awake recordings $(178,186)$ and the anesthetized recordings $(182,183)$. Awake ERPs comprise 3-4 negative and positive components, and the anesthetized recordings feature only one large positive component. The polarity of the deviance-detection effects is also different, with negative deflections in response to the deviant in the awake animals, and positive deflections in anesthetized animals. Such trends can be similarly observed in other studies (Table 4), with the majority differences between the deviant and the standard being positive in anesthetized rats and negative in awake rats. These findings illustrate that deviance-detection need not be a response that exactly mimics the human MMN (insofar as being of the same polarity). Indeed human mismatch responses (MMR) change from negative to positive in polarity when the recording location is moved from fronto-centrally sites to the mastoid when recorded using a nose reference (189).

The remainder of studies examining epidural ERPs in oddball paradigms use either the deviant-alone to control for adaptation, or use no adaptation control at all. Although the deviantalone sequence may overestimate the contribution of adaptation (165), three of the five studies utilizing this control sequence find evidence for controlled MMR recorded from epidural electrodes $(179,180,187)$. Of those epidural studies that did not implement a control for adaptation, several did not use simple frequency deviants (which are highly predisposed to be affected by adaptation mechanisms in the A1), but rather used more complex deviants that presumably elicited responses that would not be so readily perturbed by neural adaptation. For instance, Roger et al. (181) measured responses to duration deviants [which are not affected by adaptation in the A1 to the same degree as frequency deviants; (169)], and found larger responses to duration deviants (181). In addition, Ruusuvirta et al. (174) examined responses to duration deviants in combination with stimulus onset asynchrony deviants, and found evidence for larger deviant responses (compared to standards) only in the condition in which the deviant occurred earlier than expected and deviated in duration, indicating a possible threshold level for deviance that needs to be reached before a deviance-detection-like response iselicited (174). However, without the use of a many-standards (or even a deviant-alone) control, it remains difficult to conclude that such responses are completely independent of adaptation effects. Although tone duration is coded in a different way to the frequency, and previous studies have demonstrated that adaptation mechanisms for duration are not as robust as they are for frequency (169), this was examined in the auditory cortex only, and it cannot be ruled out that another region (or network of regions) adapts to stimulus duration in the same way as the auditory cortex does for frequency. These studies show that when using methods that detect shifts in potential at a network-level (i.e., a large spatial scale), signs of human-like MMR (independent of adaptation) are evident in animals.

\section{HOW DOES ANIMAL RESEARCH AUGMENT HUMAN RESEARCH ON MMN?}

Animal models are an ideal tool with which to investigate the underlying neurobiology of MMR because of the ability to perform more invasive and selective neurobiological manipulations (e.g., drug microinjection to specific regions). In addition, the comprehensive genetic toolkit available for mouse models will enable researchers to determine the role of specific genes and neural populations in the generation of MMR using transgenic animals and optogenetics. With a consensus emerging regarding the ideal recording method (epidural) and the current preferred control to use (many-standards) to examine MMR (adaptation and deviance detection) in animal models, the time is ripe for further studies examining the neurobiology of these elements of MMR, using pharmacological, developmental, and genetic manipulations. Unfortunately, few studies implement a control for adaptation effects (or if they do, do not adequately report drug effects on these), and it is therefore difficult to determine whether or not the agents given affect adaptation, deviance-detection, or both. The preferable way to investigate the pharmacology of MMN in animal models would be test different manipulations in a model that exhibits both adaptation and deviance detection [e.g., Ref. (178)], and to compare how different agents affect the responses to standards, deviants, and control stimuli; with the difference between the control and standard representing adaptation and the difference between the deviant and the control representing MMR and the effects of drug interventions on these two 
separate components can be examined. To our knowledge, no studies have tested such a model thus far.

Studies in rats and mice (like those on the macaque described above) have been used to study the role of the NMDAGluR system in MMN. These studies, in contrast to Javitt et al. (130), suggest that perturbations in NMDAR signaling can also alter responses to standard stimuli. In the absence of a control for adaptation effects, Ehrlichman et al. found that ketamine (a non-competitive NMDAGluR antagonist) concurrently increased the response to the standard (which was small to start with) and reduced the response to the deviant, albeit not to a significant degree, in awake mice (172). Tikhonravov et al. used a low $(0.1 \mathrm{mg} / \mathrm{kg})$ and high $(0.3 \mathrm{mg} / \mathrm{kg})$ dose of intraperitoneal MK-801 to examine the effects of NMDAGluR perturbation on responses to oddball stimuli, in addition to a deviant-alone control in pentobarbital-anesthetized rats (179). Responses to the deviant were more positive than the responses to the standard for the saline condition and were relatively unchanged by the low-dose of MK-801. However, the highdose of MK-801 lowered the response to the deviant and increased the response to the standard, effectively reversing the polarity of the oddball effect. The degree to which MK-801 altered the magnitude of the difference between the oddball deviant and the deviant-alone was not reported. However, the period over which the deviant was significantly different from the deviant-alone was reported: there was a positive deflection in response to the deviant (relative to deviant-alone) in saline-treated animals (indicating deviance detection), which was absent after low-dose MK-801 and reversed in polarity after high-dose MK-801 (179). The finding that low-dose MK-801 can reduce the difference between the oddball deviant and deviant-alone, without a change in the differences between deviant and standard could indicate that this dose can preferentially disrupt deviance detection, while sparing adaptation. However, the high-dose of MK-801 not only disrupted both deviance detection and adaptation but reversed the polarity of these changes. Such reversals, caused by an increase in the response to the standard and a decrease in the response to the deviant, are similar to those found after ketamine by Ehlrichman et al.

In a second study, Tikhonravov et al. investigated the effects of a low $(3 \mathrm{mg} / \mathrm{kg})$ and a high $(10 \mathrm{mg} / \mathrm{kg})$ dose of memantine on responses to oddball stimuli and deviant-alone stimuli in anesthetized rats (180). Like MK-801, memantine is an uncompetitive NMDAGluR antagonist, but unlike MK-801, is a very low-affinity antagonist and has potential as a cognitive enhancer [(190) see also discussion of memantine in Section "How do Pharmacological Manipulations Alter the MMN Process?"]. Similar to previous studies in anesthetized rats, the oddball MMR was positive in saline-treated rats. The low-dose of memantine resulted in a significant increase in the response to the deviant and the oddball MMR was significantly prolonged compared to the saline group. The high-dose of memantine, on the other hand, reduced the time over which the oddball MMR was significantly different from 0 and reversed the late phase of the difference waveform, possibly due to an increase in the response to the standard (180). With regard to deviance-detection-specific changes, the deviant was more positive than the deviant-alone in saline-treated rats, an effect that was prolonged in the low-dose memantine group. In rats treated with the high-dose of memantine, however, no deviance-detection response was observed. These findings indicate that low-dose memantine potentiates the deviance-detection response, with no significant effect on the adaptation response, but that high-dose memantine acts similarly to high-dose MK-801, affecting both adaptation and deviance detection and reversing the polarity of the oddball MMR.

Overall, these pharmacological studies suggest that NMDAGluRantagonists act in a dose-dependent fashion, with low-dose/lowaffinity antagonists facilitating deviance detection (by increasing the response to the deviant), then as NMDAGluR perturbations are increased with low-dose/high affinity antagonists, deviance detection is inhibited while adaptation is spared. However, with high-doses of high affinity blockers (ketamine and MK-801), the response to the standard is increased, thus indicating impaired adaptation. The selective impairment of deviance detection and not adaptation after MK-801 is also highlighted in (169), where it was reported that subcutaneous MK-801 (maximum dose, $0.1 \mathrm{mg} / \mathrm{kg}$ ) reduced responses to both the deviant and the standard together, while preserving the difference between them, indicating that this dose did not affect neural adaptation in A1, similar to findings in the study in which the same drug was given intraperitoneally (179). These studies indicate that the mechanism by which NMDAGluR-antagonists may reduce the MMN may be rather complex, with the dose and affinity of the antagonist interacting with adaptation and deviance-detection resulting in varied effects on these elements of the MMN. This animal work highlights a complexity in the role of NMDAGluRs in the generation of MMRs that was not discovered in human studies using NMDAGluR-antagonists, most likely due to the smaller dose-range, smaller sample size, and lack of consistent reporting of the response to standards seen in the human work. This animal work therefore highlights the need to examine a larger dose-range, as well as the need for consistent reporting of both standard and deviant responses in human pharmacological MMN studies.

Several of the previously mentioned animal pharmacological studies have similar weaknesses highlighted for the human studies. While $(179,180)$ used a control for adaptation (the deviantalone control), they did not report directly on the magnitude of responses to the standard, the deviant and the deviant-alone control, thus making the interpretation of the mechanisms affected by pharmacological agents very problematic. While these animal model investigations are still in their infancy, the promise of such models is far-reaching. Future investigations will be able to focus on a range of doses of NMDAGluR-antagonists in paradigms in which adaptation and deviance detection are welldescribed, to further explore the role of NMDAGluR signaling in both of these components. In addition, NMDAGluR-antagonists can be infused directly into regions of interests [as performed by Javitt et al. (130)], to determine where NMDAGluR signaling is important for MMR. Further, high-doses of muscimol [a Gamma-Amino Butyric Acid (A) agonist] can be infused to completely inactivate regions to determine their contribution to deviance detection. For example (174) found evidence of MMR in rat hippocampus - the degree to which these contribute to epidural-recorded MMR can be determined by infusing muscimol into selected hippocampal regions. In addition, animal models of 
schizophrenia-like reductions in MMN could possibly be developed. (173) used transgenic mice heterozygous for neuregulin 1 ( $n$ rgl; an hypothesized schizophrenia-susceptibility gene) and found a reversal in polarity of the oddball MMR in nrg1 mutants compared to wild type mice. However, this study did not adopt a control for adaptation effects, so it is unknown in $n r g 1$ plays a role in adaptation or adaptation-independent deviance-detection. Experiments in our lab are currently underway to determine the effect of maternal immune activation on MMR (both adaptation and deviance detection) in rats. Maternal immune activation is a risk factor for schizophrenia and when modeled in rats and mice, is associated with numerous schizophrenia-like behavioral and neurodevelopmental outcomes, particularly those related to NMDAGluR-dysfunction (191-193). This model therefore may also exhibit schizophrenia-like changes in MMR and could be used as a potential experimental platform to examine the pathology underlying schizophrenia-like reductions in the mismatch response, and potential treatments for such alterations.

\section{CONCLUSION}

The above review supports several conclusions regarding the potential of $\mathrm{MMN}$ as a tool to study the biological processes taking place in those with (and potentially those at-risk for) schizophrenia.

\section{MEASUREMENT AND REPORTING OF MMN}

There are pros and cons to any experimental design and it is the authors' opinion that there is no optimal design for use in schizophrenia studies. To recommend an optimal design, while improving consistency in the literature, would come at the expense of the unique contributions that can be made by novel designs [see Ref. (24) for review] that can enrich our understanding of the perceptual inference within the MMN process and how gain in this signal is controlled. Furthermore, study design is often limited by mundane and yet important considerations of test duration that could render particular paradigms less feasible. However, two recommendations arise from this review. The first is that authors and journals facilitate a closer adherence to publication standards. A failing of the current literature is that a large number of studies (including some by our group) do not adhere to recommended publication standards for ERP research which stipulates the display of the original ERPs from which difference waveforms have been derived (194). By comparing research findings across species and drug studies (as above) the importance of at least reporting standard and deviant ERPs becomes clear. Secondly, while the traditional oddball paradigm provides a robust measure of the reduction in MMN amplitude in schizophrenia, protocols designed to identify constituents of the MMN process (or oddball combined with rigorous controls) introduce the capacity to begin disentangling which components of the process are in fact compromised. This advantage becomes crucial when attempting the translation of this research into animal models (see Translation to Animal Models) and arguably also to pharmacological studies (see How do Pharmacological Manipulations Alter the MMN Process?). Where feasible, future studies should consider the advantage of designs (or analysis techniques) that facilitate the differentiation between adaption effects and something more akin to true contextual deviance detection.

\section{VULNERABILITY TO SCHIZOPHRENIA}

Our review of the literature to date indicates limited support for small MMN conferring some vulnerability to schizophrenia but we consider this an open question best addressed by large longitudinal studies. It is the authors' opinion that there is much to gained by continued efforts to understand factors that influence MMN size (using novel designs, pharmacological, and animal research) in parallel to such efforts.

\section{PHARMACOLOGY AND ANIMAL MODELS OF MMN}

It seems clear from the pharmacological studies (in animals and humans) that adaptation and sensitivity to contextual deviance may show differential effects in the presence of compromised NMDAGluR function. Pharmacological, like animal studies, require indices of both to be informative about the effect of agents on the MMN process. Similar to schizophrenia studies, animal, and pharmacological studies inconsistently report on standard and deviant effects. While our review of pharmacological studies is more supportive of some agents (e.g., glutamatergic and cholinergic) than others (e.g., monoamines), our knowledge of influences on perceptual inference and learning underlying MMN continues to grow and challenge existing models [e.g., Ref. (98, 195)] and it remains possible that future paradigms may be sensitive to agents that current paradigms are not. In other areas of learning, animal models and pharmacology have provided great insight into schizophrenia [associative learning (196)] and there is good reason to suppose that this will also be true of MMN research as well as offering the potential to examine commonalities in underlying pathology. While there are many challenges in translating the potential of MMN in elucidating the pathophysiology of the schizophrenic illness, we believe the current state of research encourages scientists to pursue the many numerous potentially fruitful avenues available to achieve this goal.

\section{AUTHOR CONTRIBUTIONS}

Juanita Todd, - lead writer and overall editor. Primary contributions Sections "The Potential - Why is there so Much Interest in MMN in Schizophrenia?" "The Measurement of MMN - Is there an Optimal Paradigm with Which to Study MMN in Schizophrenia?" "How do Pharmacological Manipulations Alter the MMN Process?" and "Conclusion.” Lauren Harms - Primary contribution Section "Translation to Animal Models.” Reference manager. Patricia T. Michie - Primary contributions Sections "The Measurement of MMN - Is there an Optimal Paradigm with Which to Study MMN in Schizophrenia?" and "Does MMN-Reduction Indicate Vulnerability to Schizophrenia?” Ulrich Schall - co-writer of all sections and preparation of Tables 1-3.

\section{ACKNOWLEDGMENTS}

Our thanks are extended to Ms. Lisa Whitson and Mr. Alexander Provost who sourced many of the papers reviewed for the pharmacology section. Lauren Harms is supported by a National Health and Medical Research Council Project grant (ID1026070). Research referenced in this paper includes that supported by additional National Health and Medical Research Council Project grants (IDs 569259 and 1002995). Ulrich Schall was supported by the Schizophrenia Research Institute utilizing infrastructure funding from the New South Wales Ministry of Health and New South Wales Ministry of Trade and Investment (Australia). 


\section{REFERENCES}

1. Näätänen R. In Attention and Brain Function. Hillsdale, NJ: Lawrence Erlbaum Associates (1992).

2. Winkler I. Interpreting the mismatch negativity. J Psychophysiol (2007) 21(34):147-63. doi:10.1027/0269-8803.21.34.147

3. Kujala T, Tervaniemi M, Schroger E. The mismatch negativity in cognitive and clinical neuroscience: theoretical and methodological considerations. Biol Psychol (2007) 74:1-19. doi:10.1016/j.biopsycho.2006.06.001

4. Picton TW, Alain C, Otten L, Ritter W, Achim A. Mismatch negativity: different water in the same river. Audiol Neurootol (2000) 5:111-39. doi:10.1159/ 000013875

5. Umbricht D, Krljes S. Mismatch negativity in schizophrenia: a meta-analysis. Schizophr Res (2005) 76:1-23. doi:10.1016/j.schres.2004.12.002

6. Alho K. Cerebral generators of mismatch negativity (MMN) and its magnetic counterpart (MMNm) elicited by sound changes. Ear Hear (1995) 16:38-51. doi:10.1097/00003446-199502000-00004

7. Javitt DC, Steinschneider M, Schroeder CE, Vaughan HG Jr, Arezzo JC. Detection of stimulus deviance within primate primary auditory cortex: intracortical mechanisms of mismatch negativity (MMN) generation. Brain Res (1994) 667:192-200. doi:10.1016/0006-8993(94)91496-6

8. Ulanovsky N, Las L, Nelken I. Processing of low-probability sounds by cortical neurons. Nat Neurosci (2003) 6:391-8. doi:10.1038/nn1032

9. Näätänen R, Jacobsen T, Winkler I. Memory-based or afferent processes in mismatch negativity (MMN): a review of the evidence. Psychophysiology (2005) 42:25-32. doi:10.1111/j.1469-8986.2005.00256.x

10. May PJ, Tiitinen H. Mismatch negativity (MMN), the deviance-elicited auditory deflection, explained. Psychophysiology (2010) 47:66-122. doi:10.1111/j. 1469-8986.2009.00856.x

11. Garrido MI, Friston KJ, Kiebel SJ, Stephan KE, Baldeweg T, Kilner JM. The functional anatomy of the MMN: a DCM study of the roving paradigm. Neuroimage (2008) 42:936-44. doi:10.1016/j.neuroimage.2008.05.018

12. Garrido MI, Kilner JM, Kiebel SJ, Friston KJ. Dynamic causal modeling of the response to frequency deviants. J Neurophysiol (2009) 101:2620-31. doi:10.1152/jn.90291.2008

13. Ruhnau P, Herrmann B, Schroger E. Finding the right control: the mismatch negativity under investigation. Clin Neurophysiol (2012) 123:507-12. doi:10.1016/j.clinph.2011.07.035

14. Schmidt A, Diaconescu AO, Kometer M, Friston KJ, Stephan KE, Vollenweider FX. Modeling ketamine effects on synaptic plasticity during the mismatch negativity. Cereb Cortex (2013) 23:2394-406. doi:10.1093/cercor/ bhs 238

15. Friston K. A theory of cortical responses. Philos Trans R Soc Lond B Biol Sci (2005) 360:815-36. doi:10.1098/rstb.2005.1622

16. Winkler I, Karmos G, Naatanen R. Adaptive modeling of the unattended acoustic environment reflected in the mismatch negativity event-related potential. Brain Res (1996) 742:239-52. doi:10.1016/S0006-8993(96)01008-6

17. Lieder F, Stephan KE, Daunizeau J, Garrido MI, Friston KJ. A neurocomputational model of the mismatch negativity. PLoS Comput Biol (2013) 9:e1003288. doi:10.1371/journal.pcbi.1003288

18. Escera C, Alho K, Winkler I, Naatanen R. Neural mechanisms of involuntary attention to acoustic novelty and change. J Cogn Neurosci (1998) 10:590-604. doi:10.1162/089892998562997

19. Schroger E, Wolff C. Attentional orienting and reorienting is indicated by human event-related brain potentials. Neuroreport (1998) 9:3355-8. doi:10. 1097/00001756-199810260-00003

20. Schroger E, Wolff C. Behavioral and electrophysiological effects of taskirrelevant sound change: a new distraction paradigm. Brain Res Cogn Brain Res (1998) 7:71-87. doi:10.1016/S0926-6410(98)00013-5

21. Ahveninen J, Jaaskelainen IP, Pekkonen E, Hallberg A, Hietanen M, Naatanen $\mathrm{R}$, et al. Increased distractibility by task-irrelevant sound changes in abstinent alcoholics. Alcohol Clin Exp Res (2000) 24:1850-4. doi:10.1111/j.1530-0277. 2000.tb01989.x

22. Escera C, Alho K, Schroger E, Winkler I. Involuntary attention and distractibility as evaluated with event-related brain potentials. Audiol Neuro Otol (2000) 5:151-66. doi:10.1159/000013877

23. Näätänen R, Kujala T, Winkler I. Auditory processing that leads to conscious perception: a unique window to central auditory processing opened by the mismatch negativity and related responses. Psychophysiology (2011) 48:4-22. doi:10.1111/j.1469-8986.2010.01114.x

24. Todd J, Michie PT, Schall U, Ward PB, Catts SV. Mismatch negativity (MMN) reduction in schizophrenia - Impaired prediction-error generation, estimation or salience? Int J Psychophysiol (2012) 83:222-31. doi:10.1016/j.ijpsycho.2011. 10.003

25. Javitt DC, Grochowski S, Shelley A, Ritter W. Impaired mismatch negativity $(\mathrm{MMN})$ generation in schizophrenia as a function of stimulus deviance, probability, and interstimulus/interdeviant interval. Electroencephalogr Clin Neurophysiol (1998) 108:143-53.

26. Shelley A-M, Silipo G, Javitt DC. Diminished responsiveness of ERPs in schizophrenic subjects to changes in auditory stimulation parameters: implications for theories of cortical dysfunction. Schizophr Res (1999) 37:65-79. doi:10.1016/S0920-9964(98)00138-8

27. Sato Y, Yabe H, Todd J, Michie P, Shinozaki N, Sutoh T, et al. Impairment in activation of a frontal attention-switch mechanism in schizophrenic patients. Biol Psychol (2003) 62:49-63. doi:10.1016/S0301-0511(02)00113-8

28. Menon RR, Barta PE, Aylward EH, Richards SS, Vaughn DD, Tien AY, et al. Posterior superior temporal gyrus in schizophrenia: grey matter changes and clinical correlates. Schizophr Res (1995) 16:127-35. doi:10.1016/0920-9964(94) 00067-I

29. Pantelis C, Velakoulis D, Mcgorry PD, Wood SJ, Suckling J, Phillips LJ, et al. Neuroanatomical abnormalities before and after onset of psychosis: a cross-sectional and longitudinal MRI comparison. Lancet (2003) 361:281-8. doi:10.1016/S0140-6736(03)12323-9

30. Pantelis C, Velakoulis D, Wood SJ, Yucel M, Yung AR, Phillips LJ, et al. Neuroimaging and emerging psychotic disorders: the Melbourne ultra-high risk studies. Int Rev Psychiatry (2007) 19:371-81. doi:10.1080/09540260701512079

31. Harms MP, Wang L, Campanella C, Aldridge K, Moffitt AJ, Kuelper J, et al. Structural abnormalities in gyri of the prefrontal cortex in individuals with schizophrenia and their unaffected siblings. Br J Psychiatry (2010) 196:150-7. doi:10.1192/bjp.bp.109.067314

32. Takahashi T, Wood SJ, Yung AR, Walterfang M, Phillips LJ, Soulsby B, et al. Superior temporal gyrus volume in antipsychotic-naive people at risk of psychosis. Br J Psychiatry (2010) 196:206-11. doi:10.1192/bjp.bp.109.069732

33. Bhojraj TS, Francis AN, Montrose DM, Keshavan MS. Grey matter and cognitive deficits in young relatives of schizophrenia patients. Neuroimage (2011) 54(Suppl 1):S287-92. doi:10.1016/j.neuroimage.2010.03.069

34. Malla AK, Bodnar M, Joober R, Lepage M. Duration of untreated psychosis is associated with orbital-frontal grey matter volume reductions in first episode psychosis. Schizophr Res (2011) 125:13-20. doi:10.1016/j.schres.2010.09.021

35. Rasser PE, Schall U, Todd J, Michie PT, Ward PB, Johnston P, et al. Gray matter deficits, mismatch negativity, and outcomes in schizophrenia. Schizophr Bull (2011) 37:131-40. doi:10.1093/schbul/sbp060

36. Sweet RA, Bergen SE, Sun Z, Marcsisin MJ, Sampson AR, Lewis DA. Anatomical evidence of impaired feedforward auditory processing in schizophrenia. Biol Psychiatry (2007) 61:854-64. doi:10.1016/j.biopsych.2006.07.033

37. Lewis DA, Sweet RA. Schizophrenia from a neural circuitry perspective: advancing toward rational pharmacological therapies. J Clin Investig (2009) 119:706-16. doi:10.1172/JCI37335

38. Sweet RA, Henteleff RA, Zhang W, Sampson AR, Lewis DA. Reduced dendritic spine density in auditory cortex of subjects with schizophrenia. Neuropsychopharmacology (2009) 34:374-89. doi:10.1038/npp.2008.67

39. Deo AJ, Cahill ME, Li S, Goldszer I, Henteleff R, Vanleeuwen J-E, et al. Increased expression of Kalirin-9 in the auditory cortex of schizophrenia subjects: its role in dendritic pathology. Neurobiol Dis (2012) 45:796-803. doi:10.1016/j.nbd.2011.11.003

40. Salisbury DF, Kuroki N, Kasai K, Shenton ME, Mccarley RW. Progressive and interrelated functional and structural evidence of post-onset brain reduction in schizophrenia. Arch Gen Psychiatry (2007) 64:521-9. doi:10.1001/archpsyc. 64.5 .521

41. Gogtay N, Giedd JN, Lusk L, Hayashi KM, Greenstein D, Vaituzis AC, et al. Dynamic mapping of human cortical development during childhood through early adulthood. Proc Natl Acad Sci U S A (2004) 101:8174-9. doi:10.1073/ pnas.0402680101

42. Kasai K, Shenton ME, Salisbury DF, Hirayasu Y, Lee C-U, Ciszewski AA, et al. Progressive decrease of left superior temporal gyrus gray matter volume in 
patients with first-episode schizophrenia. Am J Psychiatry (2003) 160:156-64. doi:10.1176/appi.ajp.160.1.156

43. Javitt D, Zukin S. Recent advances in the phencyclidine model of schizophrenia. Am J Psychiatry (1991) 148:1301-8.

44. Kantrowitz J, Javitt D. N-methyl-D-aspartate (NMDA) receptor dysfunction or dysregulation: the final common pathway on the road to schizophrenia? Brain Res Bull (2010) 30:108-21. doi:10.1016/j.brainresbull.2010.04.006

45. Javitt DC, Zukin SR, Heresco-Levy U, Umbricht D. Has an angel shown the way? Etiological and therapeutic implications of the PCP/NMDA model of schizophrenia. Schizophr Bull (2012) 38:958-66. doi:10.1093/schbul/sbs069

46. Jacobsen T, Schröger E. Is there a pre-attentive memory-based comparison of pitch. Psychophysiology (2001) 38:723-7. doi:10.1111/1469-8986.3840723

47. Jacobsen T, Schröger E, Horenkamp T, Winkler I. Mismatch negativity to pitch change: varied stimulus proportions in controlling effects of neural refractoriness on human auditory event-related brain potentials. Neurosci Lett (2003) 344:79-82. doi:10.1016/S0304-3940(03)00408-7

48. Maess B, Jacobsen T, Schröger E, Friederici A. Localizing pre-attentive auditory memory-based comparison: magnetic mismatch negativity to pitch change. Neuroimage (2007) 37:561-71. doi:10.1016/j.neuroimage.2007.05.040

49. Jacobsen T, Schröger E. Measuring duration mismtach negativity. Clin Neurophysiol (2003) 114:1133-43. doi:10.1016/S1388-2457(03)00043-9

50. Schröger E, Wolff C. Mismatch response of the human brain to changes in sound location. Neuroreport (1996) 7:3005-8. doi:10.1097/00001756199611250-00041

51. Shelley AM, Ward PB, Catts SV, Michie PT, Andrews S, Mcconaghy N. Mismatch negativity: an index of a preattentive processing deficit in schizophrenia. Biol Psychiatry (1991) 30:1059-62. doi:10.1016/0006-3223(91)90126-7

52. Catts SV, Shelley AM, Ward PB, Liebert B, Mcconaghy N, Andrews S, et al. Brain potential evidence for an auditory sensory memory deficit in schizophrenia. Am J Psychiatry (1995) 152:213-9.

53. Todd J, Michie PT, Schall U, Karayanidis F, Yabe H, Naatanen R. Deviant matters: duration, frequency, and intensity deviants reveal different patterns of mismatch negativity reduction in early and late schizophrenia. Biol Psychiatry (2008) 63:58-64. doi:10.1016/j.biopsych.2007.02.016

54. Todd J, Whitson LR, Smith E, Michie PT, Schall U, Ward P. What's intact and what's not within the mismatch negativity system in schizophrenia. Psychophysiology (in press).

55. Sams M, Alho K, Naatanen R. Sequential effects on the ERP in discriminating two stimuli. Biol Psychol (1983) 17:41-58. doi:10.1016/0301-0511(83)90065-0

56. Cowan N, Winkler I, Teder W, Naatanen R. Memory prerequisites of mismatch negativity in the auditory event-related potential (ERP). J Exp Psychol Learn Mem Cogn (1993) 19:909-21. doi:10.1037/0278-7393.19.4.909

57. Bendixen A, Roeber U, Schroger E. Regularity extraction and application in dynamic auditory stimulus sequences. J Cogn Neurosci (2007) 19:1664-77. doi:10.1162/jocn.2007.19.10.1664

58. Cooper RJ, Atkinson RJ, Clark RA, Michie PT. Event-related potentials reveal modelling of auditory repetition in the brain. Int J Psychophysiol (2013) 88:74-81. doi:10.1016/j.ijpsycho.2013.02.003

59. Baldeweg T, Klugman A, Gruzelier J, Hirsch SR. Mismatch negativity potentials and cognitive impairment in schizophrenia. Schizophr Res (2004) 69:203-17. doi:10.1016/j.schres.2003.09.009

60. Dima D, Frangou S, Burge L, Braeutigam S, James AC. Abnormal intrinsic and extrinsic connectivity within the magnetic mismatch negativity brain network in schizophrenia: a preliminary study. Schizophr Res (2012) 135:23-7. doi:10.1016/j.schres.2011.12.024

61. Javitt DC, Shelley A, Ritter W. Associated deficits in mismatch negativity generation and tone matching in schizophrenia. Clin Neurophysiol (2000) 111:1733-7. doi:10.1016/S1388-2457(00)00377-1

62. Rabinowicz EF, Silipo G, Goldman R, Javitt DC. Auditory sensory dysfunction in schizophrenia: imprecision or distractibility? Arch Gen Psychiatry (2000) 57:1149-55. doi:10.1001/archpsyc.57.12.1149

63. Light GA, Swerdlow NR, Rissling AJ, Radant A, Sugar CA, Sprock J, et al. Characterization of neurophysiologic and neurocognitive biomarkers for use in genomic and clinical outcome studies of schizophrenia. PLoS One (2012) 7:e39434. doi:10.1371/journal.pone.0039434

64. Jansson LB, Parnas J. Competing definitions of schizophrenia: what can be learned from polydiagnostic studies? Schizophr Bull (2007) 33:1178-200. doi:10.1093/schbul/sbl065
65. Gottesman I, Gould T. The endophenotype concept in psychiatry: etymology and strategic intentions. Am J Psychiatry (2003) 160:636-45. doi:10.1176/appi. ajp.160.4.636

66. Umbricht D, Koller R, Schmid L, Skrabo A, Grubel C, Huber T, et al. How specific are deficits in mismatch negativity generation to schizophrenia? Biol Psychiatry (2003) 53:1120-31. doi:10.1016/S0006-3223(02)01642-6

67. Hall M, Rijsdijk F, Kalidindi S, Schulze K, Kravariti E, Kane F, et al. Genetic overlap between bipolar illness and event-related potentials. Psychol Med (2007) 37:667-78. doi:10.1017/S003329170600972X

68. Hall M, Schulze K, Rijsdijk F, Kalidindi S, Mcdonald C, Bramon E, et al. Are auditory P300 and duration MMN heritable and putative endophenotypes of psychotic bipolar disorder? A Maudsley bipolar twin and family study. Psychol Med (2009) 39:1277-87. doi:10.1017/S0033291709005261

69. Kahkonen S, Yamashita H, Rytsala H, Suominen K, Ahveninen J, Isometsa E. Dysfunction in early auditory processing in major depressive disorder revealed by combined MEG and EEG. J Psychiatry Neurosci (2007) 32:316-22.

70. Takei Y, Kumano S, Hattori S, Uehara T, Kawakubo Y, Kasai K, et al. Preattentive dysfunction in major depression: a magnetoencephalography study using auditory mismatch negativity. Psychophysiology (2009) 46:52-61. doi:10.1111/ j.1469-8986.2008.00748.x

71. Qiao Z, Yu Y, Wang L, Yang X, Qiu X, Zhang C, et al. Impaired pre-attentive change detection in major depressive disorder patients revealed by auditory mismatch negativity. Psychiatry Res (2013) 211:78-84. doi:10.1016/j. pscychresns.2012.07.006

72. Hall MH, Rijsdijk F, Picchioni M, Schulze K, Ettinger U, Toulopoulou T, et al. Substantial shared genetic influences on schizophrenia and event-related potentials. Am J Psychiatry (2007) 164:804-12. doi:10.1176/appi.ajp.164.5.804

73. Ahveninen J, Jaaskelainen IP, Osipova D, Huttunen MO, Ilmoniemi RJ, Kaprio $\mathrm{J}$, et al. Inherited auditory-cortical dysfunction in twin pairs discordant for schizophrenia. Biol Psychiatry (2006) 60:612-20. doi:10.1016/j.biopsych.2006. 04.015

74. Corlett PR, Honey GD, Fletcher PC. From prediction error to psychosis: ketamine as a pharmacological model of delusions. J Psychopharmacol (2007) 21:238-52. doi:10.1177/0269881107077716

75. Fisher DJ, Labelle A, Knott VJ. Auditory hallucinations and the mismatch negativity: processing speech and non-speech sounds in schizophrenia. Int J Psychophysiol (2008) 70:3-15. doi:10.1016/j.ijpsycho.2008.04.001

76. Fisher DJ, Grant B, Smith DM, Borracci G, Labelle A, Knott VJ. Effects of auditory hallucinations on the mismatch negativity (MMN) in schizophrenia as measured by a modified 'optimal' multi-feature paradigm. Int J Psychophysiol (2011) 81:245-51. doi:10.1016/j.ijpsycho.2011.06.018

77. Fisher DJ, Labelle A, Knott VJ. Alterations of mismatch negativity (MMN) in schizophrenia patients with auditory hallucinations experiencing acute exacerbation of illness. Schizophr Res (2012) 139:237-45. doi:10.1016/j.schres.2012. 06.004

78. Shinozaki N, Yabe H, Sato Y, Hiruma T, Sutoh T, Nashida T, et al. The difference in mismatch negativity between the acute and post-acute phase of schizophrenia. Biol Psychol (2002) 59:105-19. doi:10.1016/S0301-0511(01)00129-6

79. Zhou Z, Zhu H, Chen L. Effect of aripiprazole on mismatch negativity (MMN) in schizophrenia. PLoS One (2013) 8:e52186. doi:10.1371/journal. pone.0052186

80. Leifker FR, Patterson TL, Bowie CR, Mausbach BT, Harvey PD. Psychometric properties of performance-based measurements of functional capacity: testretest reliability, practice effects, and potential sensitivity to change. Schizophr Res (2010) 119:246-52. doi:10.1016/j.schres.2010.03.021

81. Burdick KE, Goldberg JF, Harrow M, Faull RN, Malhotra AK. Neurocognition as a stable endophenotype in bipolar disorder and schizophrenia. J Nerv Ment Dis (2006) 194:255-60. doi:10.1097/01.nmd.0000207360.70337.7e

82. Light GA, Braff DL. Mismatch negativity deficits are associated with poor functioning in schizophrenia patients. Arch Gen Psychiatry (2005) 62:127-36. doi:10.1001/archpsyc.62.2.127

83. Light GA, Braff DL. Stability of mismatch negativity deficits and their relationship to functional impairments in chronic schizophrenia. Am J Psychiatry (2005) 162:1741-3. doi:10.1176/appi.ajp.162.9.1741

84. Kiang M, Light GA, Prugh J, Coulson S, Braff DL, Kutas M. Cognitive, neurophysiological, and functional correlates of proverb interpretation abnormalities in schizophrenia. J Int Neuropsychol Soc (2007) 13:653-63. doi:10.1017/ S1355617707070816 
85. Hermens DF, Ward PB, Hodge MA, Kaur M, Naismith SL, Hickie IB. Impaired MMN/P3a complex in first-episode psychosis: cognitive and psychosocial associations. Prog Neuropsychopharmacol Biol Psychiatry (2010) 34:822-9. doi:10.1016/j.pnpbp.2010.03.019

86. Friedman T, Sehatpour P, Dias E, Perrin M, Javitt DC. Differential relationships of mismatch negativity and visual p1 deficits to premorbid characteristics and functional outcome in schizophrenia. Biol Psychiatry (2012) 71:521-9. doi:10.1016/j.biopsych.2011.10.037

87. Wynn JK, Sugar C, Horan WP, Kern R, Green MF. Mismatch negativity, social cognition, and functioning in schizophrenia patients. Biol Psychiatry (2010) 67:940-7. doi:10.1016/j.biopsych.2009.11.024

88. Green M, Kern R, Braff D, Mintz J. Neurocognitive deficits and functional outcome in schizophrenia: are we measuring the "right stuff?" Schizophr Bull (2000) 26:119-36. doi:10.1093/oxfordjournals.schbul.a033430

89. Barch DM, Carter CS, Macdonald AW III, Braver TS, Cohen JD. Contextprocessing deficits in schizophrenia: diagnostic specificity, 4-week course, and relationships to clinical symptoms. J Abnorm Psychol (2003) 112:132-43. doi:10.1037/0021-843X.112.1.132

90. Javitt DC, Shelley A-M, Silipo G, Lieberman JA. Deficits in auditory and visual context-dependent processing in schizophrenia: defining the pattern. Arch Gen Psychiatry (2000) 57:1131-7. doi:10.1001/archpsyc.57.12.1131

91. Magleby K. Modal gating of NMDA receptors. Trends Neurosci (2004) 25:231-3. doi:10.1016/j.tins.2004.03.001

92. Zhang W, Howe J, Popescu G. Distinct gating modes determine the biphasic relaxation of NMDA receptor currents. Nat Neurosci (2008) 11:1373-5. doi:10.1038/nn.2214

93. Popescu G. Modes of glutamate receptor gating. J Physiol (2012) 590:73-91. doi:10.1113/jphysiol.2011.223750

94. Wang H, Stradtman G, Xiao-Jung W, Wen-Jun G. A specialised NMDA receptor function in layer 5 recurrent microcircuitry of the adult rat prefrontal cortex. Proc Natl Acad Sci U S A (2008) 105:16791-6. doi:10.1073/pnas.0804318105

95. Wang M, Yang Y, Ching-Jung W, Nao L, Lu E, Mazer J, et al. NMDA receptors subserve persistent neuronal firing during working memory in dorsolateral prefrontal cortex. Neuron (2013) 77:736-49. doi:10.1016/j.neuron.2012.12.032

96. Miyanishi T, Sumiyoshi T, Higuchi Y, Seo T, Suzuki M. LORETA current source density for duration mismatch negativity and neuropsychological assessment in early schizophrenia. PLoS One (2013) 8:e61152. doi:10.1371/journal.pone. 0061152

97. Todd J, Myers R, Pirillo R, Drysdale K. Neuropsychological correlates of auditory perceptual inference: a mismatch negativity (MMN) study. Brain Res (2010) 1310:113-23. doi:10.1016/j.brainres.2009.11.019

98. Todd J, Provost A, Cooper G. Lasting first impressions: a conservative bias in automatic filters of the acoustic environment. Neuropsychologia (2011) 49:3399-405. doi:10.1016/j.neuropsychologia.2011.08.016

99. Cirillo M, Seidman L. Verbal declarative memory dysfunction in schizophrenia: from clinical assessment to genetics and brain mechanisms. Neuropsychol Rev (2003) 13:43-77. doi:10.1023/A:1023870821631

100. Kawakubo Y, Kasai K, Kudo N, Rogers MA, Nakagome K, Itoh K, et al. Phonetic mismatch negativity predicts verbal memory deficits in schizophrenia. Neuroreport (2006) 17:1043-6. doi:10.1097/01.wnr.0000221828.10846.ba

101. Kaur M, Battisti RA, Ward PB, Ahmed A, Hickie IB, Hermens DF. MMN/P3a deficits in first episode psychosis: comparing schizophrenia-spectrum and affective-spectrum subgroups. Schizophr Res (2011) 130:203-9. doi:10.1016/ j.schres.2011.03.025

102. Price GW, Michie PT, Johnston J, Innes-Brown H, Kent A, Clissa P, et al. A multivariate electrophysiological endophenotype, from a unitary cohort, shows greater research utility than any single feature in the Western Australian family study of schizophrenia. Biol Psychiatry (2006) 60:1-10. doi:10.1016/j.biopsych. 2005.09.010

103. Toyomaki A, Kusumi I, Matsuyama T, Kako Y, Ito K, Koyama T. Tone duration mismatch negativity deficits predict impairment of executive function in schizophrenia. Prog Neuropsychopharmacol Biol Psychiatry (2008) 32:95-9. doi:10.1016/j.pnpbp.2007.07.020

104. Yung AR, Yuen HP, Mcgorry PD, Phillips LJ, Kelly D, Dell'olio M, et al. Mapping the onset of psychosis: the comprehensive assessment of at-risk mental states. Aust NZ J Psychiatry (2005) 39:964-71. doi:10.1080/j.1440-1614.2005.01714.x

105. Jessen F, Fries T, Kucharski C, Nishimura T, Hoenig K, Maier W, et al. Amplitude reduction of the mismatch negativity in first-degree relatives of patients with schizophrenia. Neurosci Lett (2001) 309:185-8. doi:10.1016/S0304-3940(01) 02072-9

106. Michie PT, Innes-Brown H, Todd J, Jablensky AV. Duration mismatch negativity in biological relatives of patients with schizophrenia spectrum disorders. Biol Psychiatry (2002) 52:749-58. doi:10.1016/S0006-3223(02) 01379-3

107. Bramon E, Croft RJ, Mcdonald C, Virdi GK, Gruzelier JG, Baldeweg T, et al. Mismatch negativity in schizophrenia: a family study. Schizophr Res (2004) 67:1-10. doi:10.1016/S0920-9964(03)00132-4

108. Magno E, Yeap S, Thakore JH, Garavan H, De Sanctis P, Foxe JJ. Are auditoryevoked frequency and duration mismatch negativity deficits endophenotypic for schizophrenia? High-density electrical mapping in clinically unaffected first-degree relatives and first-episode and chronic schizophrenia. Biol Psychiatry (2008) 64:385-91. doi:10.1016/j.biopsych.2008.03.019

109. Hong E, Moran L, Du X, O’Donnell P, Summerfelt A. Mismatch negativity and low frequency oscillations in schizophrenia families. Clin Neurophysiol (2012) 123:1980-8. doi:10.1016/j.clinph.2012.03.011

110. Sevik AE, Anil Yagcioglu AE, Yagcioglu S, Karahan S, Gurses N, Yildiz M. Neuropsychological performance and auditory event related potentials in schizophrenia patients and their siblings: a family study. Schizophr Res (2011) 130:195-202. doi:10.1016/j.schres.2011.04.018

111. Brockhaus-Dumke A, Tendolkar I, Pukrop R, Schultze-Lutter F, Klosterkotter J, Ruhrmann S. Impaired mismatch negativity generation in prodromal subjects and patients with schizophrenia. Schizophr Res (2005) 73:297-310. doi:10.1016/j.schres.2004.05.016

112. Atkinson RJ, Michie PT, Schall U. Duration mismatch negativity and P3a in first-episode psychosis and individuals at ultra-high risk of psychosis. Biol Psychiatry (2012) 71:98-104. doi:10.1016/j.biopsych.2011.08.023

113. Jahshan C, Cadenhead KS, Rissling AJ, Kirihara K, Braff DL, Light GA. Automatic sensory information processing abnormalities across the illness course of schizophrenia. Psychol Med (2012) 42:85-97. doi:10.1017/S0033291711001061

114. Shaikh M, Valmaggia L, Broome MR, Dutt A, Lappin J, Day F, et al. Reduced mismatch negativity predates the onset of psychosis. Schizophr Res (2012) 134:42-8. doi:10.1016/j.schres.2011.09.022

115. Higuchi Y, Sumiyoshi T, Seo T, Miyanishi T, Kawasaki Y, Suzuki M. Mismatch negativity and cognitive performance for the prediction of psychosis in subjects with at-risk mental state. PLoS One (2013) 8:e54080. doi:10.1371/journal. pone. 0054080

116. Nagai T, Tada M, Kirihara K, Noriaki Y, Hashimoto R, Araki T, et al. Auditory mismatch negativity and $\mathrm{P} 3 \mathrm{a}$ in response to duration and frequency changes in the early stages of psychosis. Schizophr Res (2013) 150:547-54 doi:10.1016/j.schres.2013.08.005

117. Perez V, Woods S, Roach B, Ford J, Mcglashan T, Vh S, et al. Automatic auditory processing deficits in schizophrenia and clinically high-risk patients: forecasting psychosis risk with mismatch negativity. Biol Psychiatry (2013). doi:10.1016/j.biopsych.2013.07.038

118. Bodatsch M, Ruhrmann S, Wagner M, Muller R, Schultze-Lutter F, Frommann I, et al. Prediction of psychosis by mismatch negativity. Biol Psychiatry (2011) 69:959-66. doi:10.1016/j.biopsych.2010.09.057

119. Oranje B, Van Berckel BN, Kemner C, Van Ree JM, Kahn RS, Verbaten MN. The effects of a sub-anaesthetic dose of ketamine on human selective attention. Neuropsychopharmacology (2000) 22:293-302. doi:10.1016/S0893-133X(99) 00118-9

120. Umbricht D, Schmid L, Koller R, Vollenweider FX, Hell D, Javitt DC. Ketamineinduced deficits in auditory and visual context-dependent processing in healthy volunteers: implications for models of cognitive deficits in schizophrenia. Arch Gen Psychiatry (2000) 57:1139-47. doi:10.1001/archpsyc.57.12.1139

121. Kreitschmann-Andermahr I, Rosburg T, Demme U, Gaser E, Nowak H, Sauer H. Effect of ketamine on the neuromagnetic mismatch field in healthy humans. Cogn Brain Res (2001) 12:109-16. doi:10.1016/S0926-6410(01)00043-X

122. Umbricht D, Vollenweider FX, Schmid L, Grubel C, Skrabo A, Huber T, et al. Effects of the 5-HT2A agonist psilocybin on mismatch negativity generation and $\mathrm{AX}$-continuous performance task: implications for the neuropharmacology of cognitive deficits in schizophrenia. Neuropsychopharmacology (2003) 28:170-81. doi:10.1038/sj.npp.1300005

123. Korostenskaja M, Nikulin VV, Kicic D, Nikulina AV, Kahkonen S. Effects of NMDA receptor antagonist memantine on mismatch negativity. Brain Res Bull (2007) 72:275-83. doi:10.1016/j.brainresbull.2007.01.007 
124. Heekeren K, Daumann J, Neukirch A, Stock C, Kawohl W, Norra C, et al. Mismatch negativity generation in the human 5HT2A agonist and NMDA antagonist model of psychosis. Psychopharmacology (2008) 199:77-88. doi:10.1007/ s00213-008-1129-4

125. Roser P, Haussleiter IS, Chong H-J, Maier C, Kawohl W, Norra C, et al. Inhibition of cerebral type 1 cannabinoid receptors is associated with impaired auditory mismatch negativity generation in the ketamine model of schizophrenia. Psychopharmacology (2011) 218:611-20. doi:10.1007/s00213-011-2352-y

126. Schmidt A, Bachmann R, Kometer M, Csomor PA, Stephan KE, Seifritz E, et al. Mismatch negativity encoding of prediction errors predicts S-ketamineinduced cognitive impairments. Neuropsychopharmacology (2012) 37:865-75. doi:10.1038/npp.2011.261

127. Gunduz-Bruce H, Reinhart RMG, Roach BJ, Gueorguieva R, Oliver S, D’Souza DC, et al. Glutamatergic Modulation of Auditory Information Processing in the Human Brain. Biol Psychiatry (2012) 71:969-77. doi:10.1016/j.biopsych. 2011.09.031

128. Harrison PJ, Weinberger DR. Schizophrenia genes, gene expression, and neuropathology: on the matter of their convergence. Mol Psychiatry (2005) 10:40-68. doi:10.1038/sj.mp.4001558

129. Lewis DA, Moghaddam B. Cognitive dysfunction in schizophrenia: convergence of gamma-aminobutyric acid and glutamate alterations. Arch Neurol (2006) 63:1372-6. doi:10.1001/archneur.63.10.1372

130. Javitt DC, Steinschneider M, Schroeder CE, Arezzo JC. Role of cortical Nmethyl-D-aspartate receptors in auditory sensory memory and mismatch negativity generation: implications for schizophrenia. Proc Natl Acad Sci U S A (1996) 93:11962-7. doi:10.1073/pnas.93.21.11962

131. Umbricht D, Koller R, Vollenweider FX, Schmid L. Mismatch negativity predicts psychotic experiences induced by NMDA receptor antagonist in healthy volunteers. Biol Psychiatry (2002) 51:400-6. doi:10.1016/S0006-3223(01)01242-2

132. Stephan KE, Baldeweg T, Friston KJ. Synaptic plasticity and dysconnection in schizophrenia. Biol Psychiatry (2006) 59:929-39. doi:10.1016/j.biopsych.2005. 10.005

133. Jaaskelainen IP, Lehtokoski A, Alho K, Kujala T, Pekkonen E, Sinclair JD, et al. Low dose of ethanol suppresses mismatch negativity of auditory event-related potentials. Alcohol Clin Exp Res (1995) 19:607-10.

134. Jaaskelainen IP, Pekkonen E, Hirvonen J, Sillanaukee P, Naatanen R. Mismatch negativity subcomponents and ethyl alcohol. Biol Psychol (1996) 43:13-25. doi:10.1016/0301-0511(95)05174-0

135. Lin H, Vicini S, Hsu F-C, Doshi S, Takano H, Coulter DA, et al. Axonal 7 nicotinic ACh receptors modulate presynaptic NMDA receptor expression and structural plasticity of glutamatergic presynaptic boutons. Proc Natl Acad Sci U S A (2010) 107:16661-6. doi:10.1073/pnas.1007397107

136. Moran RJ, Campo P, Symmonds M, Stephan KE, Dolan RJ, Friston KJ. Free energy, precision and learning: the role of cholinergic neuromodulation. J Neurosci (2013) 33:8227-36. doi:10.1523/JNEUROSCI.4255-12.2013

137. Harkrider AW, Hedrick MS. Acute effect of nicotine on auditory gating in smokers and non-smokers. Hear Res (2005) 202:114-28. doi:10.1016/j.heares. 2004.11.009

138. Baldeweg T, Wong D, Stephan KE. Nicotinic modulation of human auditory sensory memory: evidence from mismatch negativity potentials. Int $J$ Psychophysiol (2006) 59:49-58. doi:10.1016/j.ijpsycho.2005.07.014

139. Dunbar G, Boeijinga PH, Demazieres A, Cisterni C, Kuchibhatla R, Wesnes K, et al. Effects of TC-1734 (AZD3480), a selective neuronal nicotinic receptor agonist, on cognitive performance and the EEG of young healthy male volunteers. Psychopharmacology (2007) 191:919-29. doi:10.1007/s00213-006-0675$\mathrm{x}$

140. Knott VJ, Bolton K, Heenan A, Shah D, Fisher DJ, Villeneuve C. Effects of acute nicotine on event-related potential and performance indices of auditory distraction in nonsmokers. Nicotine Tob Res (2009) 11:519-30. doi:10.1093/ntr/ntp044

141. Martin LF, Davalos DB, Kisley MA. Nicotine enhances automatic temporal processing as measured by the mismatch negativity waveform. Nicotine Tob Res (2009) 11:698-706. doi:10.1093/ntr/ntp052

142. Inami R, Kirino E, Inoue R, Arai H. Transdermal nicotine administration enhances automatic auditory processing reflected by mismatch negativity. Pharmacol Biochem Behav (2005) 80:453-61. doi:10.1016/j.pbb.2005.01.001

143. Knott VJ, Scherling CS, Blais CM, Camarda J, Fisher DJ, Millar A, et al. Acute nicotine fails to alter event-related potential or behavioral performance indices of auditory distraction in cigarette smokers. Nicotine Tob Res (2006) 8:263-73. doi:10.1080/14622200600576669

144. Solowij N, Michie PT. Cannabis and cognitive dysfunction: parallels with endophenotypes of schizophrenia? J Psychiatry Neurosci (2007) 32: 30-52.

145. Murray RM, Lappin J, Di Forti M. Schizophrenia: from developmental deviance to dopamine dysregulation. Eur Neuropsychopharmacol (2008) 18(Suppl 3):S129-34. doi:10.1016/j.euroneuro.2008.04.002

146. Solowij N, Yucel M, Respondek C, Whittle S, Lindsay E, Pantelis C, et al. Cerebellar white-matter changes in cannabis users with and without schizophrenia. Psychol Med (2011) 41:2349-59. doi:10.1017/S003329171100050X

147. Yucel M, Bora E, Lubman DI, Solowij N, Brewer WJ, Cotton SM, et al. The impact of cannabis use on cognitive functioning in patients with schizophrenia: a meta-analysis of existing findings and new data in a first-episode sample. Schizophr Bull (2012) 38:316-30. doi:10.1093/schbul/sbq079

148. Bossong MG, Niesink RJM. Adolescent brain maturation, the endogenous cannabinoid system and the neurobiology of cannabis-induced schizophrenia. Prog Neurobiol (2010) 92:370-85. doi:10.1016/j.pneurobio.2010.06.010

149. Juckel G, Roser P, Nadulski T, Stadelmann AM, Gallinat J. Acute effects of Delta9-tetrahydrocannabinol and standardized cannabis extract on the auditory evoked mismatch negativity. Schizophr Res (2007) 97:109-17. doi:10.1016/ j.schres.2007.08.015

150. Stadelmann AM, Roser P, Arning L, Gallinat J, Epplen JT, Juckel G. Acute effects of delta9-tetrahydrocannabinol on the auditory evoked mismatch negativity are modulated by the NRG1 gene. Pharmacopsychiatry (2010) 43:194-5. doi:10.1055/s-0030-1254088

151. Boucher A, Arnold J, Duffy L, Schofield P, Micheau J, Karl T. Heterozygous neuregulin 1 mice are more sensitive to the behavioural effects of Delta9tetrahydrocannabinol. Psychopharmacology (2007) 192:325-36. doi:10.1007/ s00213-007-0721-3

152. Javitt DC, Doneshka P, Grochowski S, Ritter W. Impaired mismatch negativity generation reflects widespread dysfunction of working memory in schizophrenia. Arch Gen Psychiatry (1995) 52:550-8. doi:10.1001/archpsyc.1995. 03950190032005

153. Lawler CP, Prioleau C, Lewis MM, Mak C, Jiang D, Schetz JA, et al. Interactions of the novel antipsychotic aripiprazole (OPC-14597) with dopamine and serotonin receptor subtypes. Neuropsychopharmacology (1999) 20:612-27. doi:10.1016/S0893-133X(98)00099-2

154. Shapiro DA, Renock S, Arrington E, Chiodo LA, Liu LX, Sibley DR, et al. Aripiprazole, a novel atypical antipsychotic drug with a unique and robust pharmacology. Neuropsychopharmacology (2003) 28:1400-11. doi:10.1038/sj.npp. 1300203

155. Mailman R. GPCR functional selectivity has therapeutic impact. Trends Pharmacol Sci (2007) 28:390-6. doi:10.1016/j.tips.2007.06.002

156. Han M, Huang X-F, Deng C. Aripiprazole differentially affects mesolimbic and nigrostriatal dopaminergic transmission: implications for long-term drug efficacy and low extrapyramidal side-effects. Int J Neuropsychopharmacol (2009) 12:941-52. doi:10.1017/S1461145709009948

157. Mervaala E, Alhainen K, Helkala EL, Partanen J, Jousmaki V, Vayrynen M, et al. Electrophysiological and neuropsychological effects of a central alpha 2antagonist atipamezole in healthy volunteers. Behav Brain Res (1993) 55:85-91. doi:10.1016/0166-4328(93)90010-N

158. Schreiber H, Stolz-Born G, Pietrowsky R, Kornhuber HH, Fehm HL, Born J. Improved event-related potential signs of selective attention after the administration of the cholecystokinin analog ceruletide in healthy persons. Biol Psychiatry (1995) 37:702-12. doi:10.1016/0006-3223(94)00207-J

159. Kahkonen S, Ahveninen J, Jaaskelainen IP, Kaakkola S, Naatanen R, Huttunen J, et al. Effects of haloperidol on selective attention: a combined whole-head MEG and high-resolution EEG study. Neuropsychopharmacology (2001) 25:498-504. doi:10.1016/S0893-133X(01)00255-X

160. Pekkonen E, Hirvonen J, Ahveninen J, Kaehkoenen S, Kaakkola S, Huttunen J, et al. Memory-based comparison process not attenuated by haloperidol: a combined MEG and EEG study. Neuroreport (2002) 13:177-81. doi:10.1097/ 00001756-200201210-00040

161. Ahveninen J, Kahkonen S, Pennanen S, Liesivuori J, Ilmoniemi RJ, Jaaskelainen IP. Tryptophan depletion effects on EEG and MEG responses suggest serotonergic modulation of auditory involuntary attention in humans. Neuroimage (2002) 16:1052-61. doi:10.1006/nimg.2002.1142 
162. Leung S, Croft RJ, Baldeweg T, Nathan PJ. Acute dopamine $\mathrm{D}(1)$ and $\mathrm{D}(2)$ receptor stimulation does not modulate mismatch negativity $(\mathrm{MMN})$ in healthy human subjects. Psychopharmacology (2007) 194:443-51. doi:10.1007/ s00213-007-0865-1

163. Korostenskaja M, Kicic D, Kahkonen S. The effect of methylphenidate on auditory information processing in healthy volunteers: a combined EEG/ MEG study. Psychopharmacology (2008) 197:475-86. doi:10.1007/s00213-0071065-8

164. Leung S, Croft RJ, Guille V, Scholes K, O’Neill BV, Phan KL, et al. Acute dopamine and/or serotonin depletion does not modulate mismatch negativity (MMN) in healthy human participants. Psychopharmacology (2010) 208:233-44. doi:10.1007/s00213-009-1723-0

165. Nelken I, Ulanovsky N. Mismatch negativity and stimulus-specific adaptation in animal models. J Psychophysiol (2007) 21:214-23. doi:10.1523/JNEUROSCI. 6045-11.2012

166. Ulanovsky N, Las L, Farkas D, Nelken I. Multiple time scales of adaptation in auditory cortex neurons. J Neurosci (2004) 24:10440-53. doi:10.1523/ JNEUROSCI.1905-04.2004

167. Eriksson J, Villa AE. Event-related potentials in an auditory oddball situation in the rat. Biosystems (2005) 79:207-12. doi:10.1016/j.biosystems.2004.09.017

168. von der Behrens W, Bauerle P, Kossl M, Gaese BH. Correlating stimulus-specific adaptation of cortical neurons and local field potentials in the awake rat. J Neurosci (2009) 29:13837-49. doi:10.1523/JNEUROSCI.3475-09.2009

169. Farley BJ, Quirk MC, Doherty JJ, Christian EP. Stimulus-specific adaptation in auditory cortex is an NMDA-independent process distinct from the sensory novelty encoded by the mismatch negativity. J Neurosci (2010) 30:16475-84. doi:10.1523/JNEUROSCI.2793-10.2010

170. Taaseh N, Yaron A, Nelken I. Stimulus-specific adaptation and deviance detection in the rat auditory cortex. PLoS One (2011) 6:e23369. doi:10.1371/journal. pone.0023369

171. Fishman YI, Steinschneider M. Searching for the mismatch negativity in primary auditory cortex of the awake monkey: deviance detection or stimulus specific adaptation? J Neurosci (2012) 32:15747-58. doi:10.1523/JNEUROSCI. 2835- 12.2012

172. Ehrlichman RS, Maxwell CR, Majumdar S, Siegel SJ. Deviance-elicited changes in event-related potentials are attenuated by ketamine in mice. J Cogn Neurosci (2008) 20:1403-14. doi:10.1162/jocn.2008.20097

173. Ehrlichman RS, Luminais SN, White SL, Rudnick ND, Ma N, Dow HC, et al. Neuregulin 1 transgenic mice display reduced mismatch negativity, contextual fear conditioning and social interactions. Brain Res (2009) 1294:116-27. doi:10.1016/j.brainres.2009.07.065

174. Ruusuvirta T, Lipponen A, Pellinen E, Penttonen M, Astikainen P. Auditory cortical and hippocampal-system mismatch responses to duration deviants in urethane-anesthetized rats. PLoS One (2013) 8:e54624. doi:10.1371/journal. pone.0054624

175. Imada A, Morris A, Wiest MC. Deviance detection by a P3-like response in rat posterior parietal cortex. Front Integr Neurosci (2012) 6:127. doi:10.3389/fnint. 2012.00127

176. Pincze Z, Lakatos P, Rajkai C, Ulbert I, Karmos G. Separation of mismatch negativity and the $\mathrm{N} 1$ wave in the auditory cortex of the cat: a topographic study. Clin Neurophysiol (2001) 112:778-84. doi:10.1016/S1388-2457(01)00509-0

177. Umbricht D, Vyssotki D, Latanov A, Nitsch R, Lipp HP. Deviance-related electrophysiological activity in mice: is there mismatch negativity in mice? Clin Neurophysiol (2005) 116:353-63. doi:10.1016/j.clinph.2004.08.015

178. Jung F, Stephan KE, Backes H, Moran R, Gramer M, Kumagai T, et al. Mismatch responses in the awake rat: evidence from epidural recordings of auditory cortical fields. PLoS One (2013) 8:e63203. doi:10.1371/journal.pone.0063203

179. Tikhonravov D, Neuvonen T, Pertovaara A, Savioja K, Ruusuvirta T, Naatanen R, et al. Effects of an NMDA-receptor antagonist MK-801 on an MMNlike response recorded in anesthetized rats. Brain Res (2008) 1203:97-102. doi:10.1016/j.brainres.2008.02.006

180. Tikhonravov D, Neuvonen T, Pertovaara A, Savioja K, Ruusuvirta T, Naatanen R, et al. Dose-related effects of memantine on a mismatch negativity-like response in anesthetized rats. Neuroscience (2010) 167:1175-82. doi:10.1016/j. neuroscience.2010.03.014

181. Roger C, Hasbroucq T, Rabat A, Vidal F, Burle B. Neurophysics of temporal discrimination in the rat: a mismatch negativity study. Psychophysiology (2009) 46:1028-32. doi:10.1111/j.1469-8986.2009.00840.x
182. Ahmed M, Mallo T, Leppanen PH, Hamalainen J, Ayravainen L, Ruusuvirta T, et al. Mismatch brain response to speech sound changes in rats. Front Psychol (2011) 2:283. doi:10.3389/fpsyg.2011.00283

183. Astikainen P, Stefanics G, Nokia M, Lipponen A, Cong F, Penttonen M, et al. Memory-based mismatch response to frequency changes in rats. PLoS One (2011) 6:e24208. doi:10.1371/journal.pone.0024208

184. Lazar R, Metherate R. Spectral interactions, but no mismatch negativity, in auditory cortex of anesthetized rat. Hear Res (2003) 181:51-6. doi:10.1016/ S0378-5955(03)00166-7

185. Astikainen P, Ruusuvirta T, Wikgren J, Penttonen M. Memory-based detection of rare sound feature combinations in anesthetized rats. Neuroreport (2006) 17:1561-4. doi:10.1097/01.wnr.0000233097.13032.7d

186. Nakamura T, Michie PT, Fulham WR, Todd J, Budd TW, Schall U, et al. Epidural auditory event-related potentials in the rat to frequency and duration deviants: evidence of mismatch negativity? Front Psychol (2011) 2:367. doi:10.3389/fpsyg.2011.00367

187. Ruusuvirta T, Penttonen M, Korhonen T. Auditory cortical event-related potentials to pitch deviances in rats. Neurosci Lett (1998) 248:45-8. doi:10.1016/ S0304-3940(98)00330-9

188. Ruusuvirta T, Koivisto K, Wikgren J, Astikainen P. Processing of melodic contours in urethane-anaesthetized rats. Eur J Neurosci (2007) 26:701-3. doi:10.1111/j.1460-9568.2007.05687.x

189. Näätänen R. The role of attention in auditory information processing as revealed by event-related potentials and other brain measures of cognitive function. Behav Brain Sci (1990) 13:201-33. doi:10.1017/S0140525X00078407

190. Zoladz PR, Campbell AM, Park CR, Schaefer D, Danysz W, Diamond DM. Enhancement of long-term spatial memory in adult rats by the noncompetitive NMDA receptor antagonists, memantine and neramexane. Pharmacol Biochem Behav (2006) 85:298-306. doi:10.1016/j.pbb.2006.08.011

191. Zuckerman L, Weiner I. Maternal immune activation leads to behavioral and pharmacological changes in the adult offspring. J Psychiatr Res (2005) 39:311-23. doi:10.1016/j.jpsychires.2004.08.008

192. Meyer U, Nyffeler M, Yee BK, Knuesel I, Feldon J. Adult brain and behavioral pathological markers of prenatal immune challenge during early/middle and late fetal development in mice. Brain Behav Immun (2008) 22:469-86. doi:10.1016/j.bbi.2007.09.012

193. Vorhees CV, Graham DL, Braun AA, Schaefer TL, Skelton MR, Richtand NM, et al. Prenatal immune challenge in rats: altered responses to dopaminergic and glutamatergic agents, prepulse inhibition of acoustic startle, and reduced route-based learning as a function of maternal body weight gain after prenatal exposure to poly IC. Synapse (2012) 66:725-37. doi:10.1002/syn.21561

194. Picton TW, Bentin S, Berg P, Donchin E, Hillyard SA, Johnson R, et al. Guidelines for using human event-related potentials to study cognition: Recording standards and publication criteria. Psychophysiology (2000) 37:127-52. doi:10.1111/1469-8986.3720127

195. Todd J, Heathcote A, Mullens D, Whitson LR, Provost A, Winkler I. What controls gain in gain control? Mismatch negativity (MMN), priors and system biases. Brain Topogr (in press).

196. Hall J, Romaniuk L, Mcintosh AM, Steele JD, Johnstone EC, Lawrie SM. Associative learning and the genetics of schizophrenia. Trends Neurosci (2009) 32:359-65. doi:10.1016/j.tins.2009.01.011

Conflict of Interest Statement: The authors declare that the research was conducted in the absence of any commercial or financial relationships that could be construed as a potential conflict of interest.

Received: 01 September 2013; accepted: 04 December 2013; published online: 18 December 2013.

Citation: Todd J, Harms L, Schall U and Michie PT (2013) Mismatch negativity: translating the potential. Front. Psychiatry 4:171. doi: 10.3389/fpsyt.2013.00171

This article was submitted to Schizophrenia, a section of the journal Frontiers in Psychiatry.

Copyright (c) 2013 Todd, Harms, Schall and Michie. This is an open-access article distributed under the terms of the Creative Commons Attribution License (CC BY). The use, distribution or reproduction in other forums is permitted, provided the original author(s) or licensor are credited and that the original publication in this journal is cited, in accordance with accepted academic practice. No use, distribution or reproduction is permitted which does not comply with these terms. 